\title{
Spatiotemporal variability of water vapor over Turkey from GNSS observations during 2009-2017 and predictability of ERA- Interim and ARMA model
}

\author{
Kutubuddin Ansari ${ }^{1,2^{*}}$, Ozsen Corumluoglu², Sampad Kumar Panda ${ }^{3}$ and Payal Verma ${ }^{4}$
}

\begin{abstract}
The present paper investigates precipitable water vapor (PWV) variations over the lower middle latitude Turkish region from the International GNSS Services (IGS) and Turkish Permanent GNSS Network (TPGN) observations. The diurnal, seasonal, annual, and rainfall time behavior of PWV and their relative deviations are presented covering the period from 2009 to 2017. Additionally, the predictions from Auto Regressive Moving Average (ARMA) model and ERA-Interim reanalysis datasets are analyzed to understand their effectiveness over the region. In the first observation, diurnal profile indicates maximum value of PWV over the ocean climate regions whereas minimum value is noticed over the semi-arid continental climate areas of Turkey. The seasonal maximum value of PWV is observed in June solstice followed by September equinox and the lowest value is seen in December solstice followed March equinox. The studies also cover annual variation, grand-mean of tropospheric PWV and PWV intensity from the TPGN confirming the range of PWV between 0 to $45 \mathrm{~mm}$. The PWV time series during 2009 to 2017 exhibit a strong annual variation at all sites, with distinctive peaks and dips occurring approximately in summer and winter, respectively. The precipitation plots displayed a clear increasing pattern in summer but the values are less in winter. However, the annual relative deviation of PWV lies in the range of -0.5 to 1.5 units for all stations. The highest grand-mean of PWV is registered in $2010(\sim 22 \mathrm{~mm})$ whereas the lowest value is seen in $2011(\sim 11 \mathrm{~mm})$. The spatial variation of PWW shows that the northern boundary of the Turkey, western part of the country and Northern Cyprus have higher magnitude of PWW while the other part of the country like Central and Eastern Turkey have the lower magnitudes of PW. PWV analysis during the precipitation period reconfirms that the rainfall pattern is not necessary to follow the PWV time series due to interlinked atmospheric processes. However, we found the PWW predictability of ARMA model is relatively better than the ERA-Interim model. Comprehensive analysis of TPGN data over the region may complement towards a better understanding of the tropospheric dynamics, their effects and the future refinements of atmospheric models over the lower middle latitude Turkish region.
\end{abstract}

Keywords: TPGN, PWW, ARMA, ERA-Interim

\footnotetext{
* Correspondence: kdansarix@gmail.com

'Department of Civil and Geomatics Engineering, Kathmandu University,

Dhulikhel, Nepal

${ }^{2}$ Department of Geomatics Engineering, Izmir Katip Celebi University, Izmir,

Turkey

Full list of author information is available at the end of the article
} 


\section{Introduction}

The troposphere is the lowermost layer of earth's atmosphere extending approximately 7 to $20 \mathrm{~km}$ from the earth's surface where almost all weather takes place. It carries about $75-80 \%$ of the total atmospheric mass and about $99 \%$ of the total mass of water vapor and aerosols. Hence, following ionospheric layer, the tropospheric layer has been playing a challenging role in the Communication, Navigation and Surveillance (CNS) applications by offering neutral atmospheric delays in the traversing signals (Ansari et al. 2018). In particular, the modern navigation and positioning operations through the Global Navigation Satellite System (GNSS) signals suffer a considerable range delay error due the water vapor, temperature and pressure content in the troposphere which in turn degrades the positioning precision (Hadas et al. 2016). Unlike ionospheric (dispersive) delays, the tropospheric (neutral) delay in dual frequency GNSS receivers cannot be mitigated through linear combination of frequencies method (Panda and Gedam 2016). Rather, it can be mitigated through modeling the wet and dry components of the troposphere. The tropospheric delay is known as the Zenith Total Delay (ZTD) and can be distinguished into two components, namely the Zenith Wet Delay (ZWD) that corresponds to the moisture content of the atmosphere and the Zenith Hydrostatic Delay (ZHD) or Zenith Dry Delay (ZDD) caused by dry air gases in the atmosphere. The ZHD can be reasonably tackled by existing empirical model (e.g. Hopfield 1972) and analytical model (e.g. Saastamoinen 1972) etc. However, the ZWD contains large uncertainties as the water vapor of the atmosphere varies significantly in spatial as well as temporal domain. There are hardly any accurate models for the wet component. Hence, the ZWD is usually estimated as unidentified parameters (Hadas et al. 2016). Incidentally, the slant wet delay in the GNSS signals can be mapped into zenith direction by using suitable mapping functions like Niell mapping function (Niell 1996) and VMF1 (Boehm et al. 2009) etc. In brief, the wet delay together with other unknown parameters like clock error and receiver coordinate uncertainties are estimated in the functional model following an empirical solution for the ZHD component of ZTD error.

Apart from modeling the tropospheric delays in GNSS positioning solutions, equivalent precipitable water vapor (PWV) from ZWD is considered as an input parameter in global hydrological cycle, weather formation, precipitations, radiation budget, latent heat transportation as well as numerical weather forecasting and climate monitoring etc. (Bianchi et al. 2016). The ZWD is directly proportional to PWV (Bevis et al. 1992). Nowadays, worldwide distributed dense network of GNSS receivers became an effective tool for the remote sensing of PWV in the troposphere, popularly named as GNSS meteorology. The water vapor in the atmosphere has a complex life series, which involves horizontal and vertical transport, precipitation and condensation. The water vapor content is an indicator for the moisture conditions in the troposphere, and serves as an index of the volume of water which could be released in the form of precipitation following the condensation (Priego et al. 2016). In many cases, the water vapor is under sampled in the typical meteorological and climate observing systems. Therefore, obtaining and exploiting additional high-quality humidity observations is essential towards the advancement of climate monitoring and forecasting. The existing PWV observing systems such as radiosonde, water vapor radiometer (WVR), and satellite remote sensing have their own advantages, but none of them are self-sufficient for multi-temporal scale PWV studies with reasonable expenses (Rocken et al. 1995; Ning et al. 2013). The longest atmospheric data from radiosonde measurements also gives very poor spatial and temporal resolution (twice daily) inspite of high operational costs. WVR is expensive and has high temporal resolution, but requires site or season specific calibration. Satellite remote sensing techniques are more accurate over oceans than over land, but hold a limitation being incapable to estimate PWV in presence of cloud cover. In the present era, GNSS meteorology has been emphasized in exploring the spatiotemporal variation of PWV homogeneously due to its all-time all weather conditions operability (HernandezPajares et al. 2001; Vedel et al. 2001). GNSS technology has proved its capability as a perfect sensor of atmospheric water vapor but still the research is ongoing in some European national meteorological institutes (Guerova et al. 2005; Morland et al. 2009).

The GNSS technique involves estimation of total Integrated Water Vapor (IWV) along the signal path from satellite to the receiver which can be mapped to its vertical equivalent through suitable mapping function. However, the process needs weighted mean temperature derived from surface temperature and the surface pressure of the atmospheric column as prerequisites which are usually recorded by the collocated meteorological sensor (Birkenheuer and Gutman 2005). Alternatively, the above prerequisites can be obtained from Numerical Weather Prediction (NWP) model or interpolation from the reanalysis datasets (Bock et al. 2005). The weighted mean temperature $\left(T_{m}\right)$ of the atmospheric column can be calculated from the vertical pressure levels of the reanalysis dataset (Wang et al. 2005) or obtained by using linear temperature $\left(T_{m}\right)$ to surface temperature $\left(T_{s}\right)$ relationship (Bevis et al. 1992). The weighted mean temperature $\left(T_{m}\right)$ also can be provided by an empirical harmonic model besides the two methods (Zhang et al. 2017). The GNSS estimated wet delay can be injected into the NWP model for improving the forecasting, particularly 
during unusual weather situations (Rohm et al. 2014). Several works have been done on real-time GNSS monitoring of water vapor over different parts of European territory demonstrate that the real-time processing quality of ZTD estimation may vary within a range of 3-10 $\mathrm{mm}$ (Hadas et al., 2013).

There are an enormous amount studies on GNSSestimated PWV distribution, variation, and trend for varying time scale over various locations across the world leaving behind a few such analysis over the Turkish territory (Ansari et al. 2016). Admittedly, observations across the Mediterranean region have proven strong relationship between precipitable water vapor content and subsequently precipitation occurrences through the regular atmospheric processes (Brenot et al. 2006). In the present paper, an investigation on lower middle latitude Turkish region has been attempted to explore the behavior of PWV variations estimated from International GNSS Services (IGS) and Turkish Permanent GNSS Network (TPGN) observables. It includes the study of diurnal, seasonal, annual and spatial as well as the cases of rainfall occurrences covering a period of almost 9 years (2009 to 2017). The TPGN comprises a network of permanent GNSS receivers in the Euro-Asian region with 138 GNSS stations, established in 1999 and continuously archiving data in a dedicated server (https://www.tkgm.gov.tr/tr/icerik/tusaga-aktif-0). The 4 IGS stations include ISTA, TUBI and ANKR distributed all over Turkey and one ARUC from Armenia. The GNSS data by post-processing provides PWV time-series of every GNSS station with 15 min temporal resolution. The GNSS-derived PWV is validated with ERA-Interim reanalysis dataset to realize their disparity over the region (http://apps.ecmwf.int/datasets/data/interim-full-daily/ levtype $=\mathrm{sfc} /$ ). The ERA-Interim has resolution of 0 . $75^{\circ} \times 0.75^{\circ}$ with 37 vertical levels and has higher analysis accuracy (4D Var), improved low-frequency variability, improved hydrological cycle, and hence will be more suitable for deriving required meteorological parameters for PWV estimation. Although there are a countable number of articles published on the reliability of ERA-Interim model at different geographical location around the world, so far our knowledge the reliability has not been explored yet over the lower middle latitude Turkish region (e.g. Madonna et al. 2014; Fantini et al. 2016). This motivated us to assess a precipitable water vapor study with GNSS observables, ERA-Interim reanalysis data set over the Turkish region. Apart from this, we tried to observe the performance of ARMA model in forecasting the tropospheric parameters over the region. The ARMA model working principle can be explained as follows:

Let $z$ denote the stationarized time series (the time series having a constant variance over time or has no trend). In technical language, we can say it has constant autocorrelations over the time. The equation for ARMA forecasting $z$ is given by:

$$
\begin{aligned}
& \text { Forecasting of } z \text { at time } t= \\
& \begin{array}{r}
\text { Constant }+ \text { sum of the weighted last } p \text { values of } z \\
\quad+\text { sum of the weighted last } q \text { forecast errors }
\end{array}
\end{aligned}
$$

Where " $p$ " and " $q$ " are small positive or negative integers called the weighted coefficients. Mostly the value of either $p$ or $q$ is taken as zero, and sum of $\mathrm{p}$ and $(p+q)$ is consider less than or equal to 3 . The equation for the predicted value of $z$ in a period $t$ up to period $t-1$ based on the observed data is expressed like this (Nau 2014):

$$
\hat{z}_{t}=\mu+\phi_{1} z_{t-1}+\ldots \ldots .+\phi_{p} z_{t-p}-\theta_{1} e_{t-1}-\ldots \ldots . .-\theta_{q} e_{t-q}
$$

Where $\mu$ is the constant term, $\phi_{k}$ is AR and $\theta_{k}$ is MA coefficient at lag $k$. The value $e_{t-k}=z_{t-k}-\hat{z}_{t-k}$ is the error in forecasting which was prepared at period $t-k$. It is notable that the error terms MA in the model are usually written with a negative sign instead of a positive sign (Nau 2014).

The mathematical equations of ARMA model in simpler form can be written as:

$$
\hat{z}_{t}=\mu+\sum_{i=1}^{p} \phi_{i} z_{t-i}-\sum_{j=1}^{q} \theta_{j} e_{t-j}
$$

The intention of this work is to forecast $(15 \mathrm{~min}$ ahead) the PWV variations at mid latitude Turkish regions during the selected period. We selected ARMA model with the order $p=1$ and $\mathrm{q}=1$. The forecasted values of PWV are evaluated with original PWV values. The preliminary outcomes indicate that ARMA model would be a successful tool for developing early warning tropospheric disturbances.

Finally, the TRMM, 3A12 version 7 rainfall data is studied to examine the variation of rainfall pattern at its correlations with the PWV over Turkish territory. The paper consist of the following Sections: a mathematical model is presented together with a short description of GNSS stations and meteorological data observations in Sect. 2. An overview of the study area and climate characteristics is shown in Sect. 3. The results and discussion of PWV variation in terms of diurnal, seasonal, annual and spatial as well as rainfall depiction has been outlined in Sect. 4. Finally, the conclusion from the analysis has been summarized in Sect. 5 .

\section{Estimation of PWV from the GNSS data}

The study involves GNSS data from four IGS stations located at Istanbul (ISTA), Ankara (ANKR), Gebze (TUBI) and Armenia (ARUC) and 138 TPGN stations across the Turkish region covering the period January 2009 to April 2017. The TPGN established in 1999 and 
continuously recoding data in Receiver Independent Exchange (RINEX) format (Ansari et al. 2017a). The geographic coordinates (latitude and longitude) of the GNSS stations are shown in Fig. 1 and Table 1. The stations used for a specific part of the study are colored in Fig. 1 and indicated in the last column of Table 1. The IGS stations data are obtained from the CDDIS data server (ftp://cddis.gsfc.nasa.gov/) and TPGN data has been downloaded by the Turkish website (TUSAGA-Aktif, https://www.tkgm.gov.tr/tr/icerik/tusaga-aktif-0). The data has been processed on a daily basis by using GAMIT (GNSS Analysis at MIT) processing software (Herring et al. 2010). The tropospheric zenith delay parameters, satellite state vectors and regional station coordinates per site on daily basis have been estimated using double difference phase observations and their phase ambiguity solutions. The ZTD is obtained at 15 min interval through the first-order Gauss-Markov process. Notable to say that PWV contains approximately $0.8 \mathrm{~mm}$ error that corresponds to $5 \mathrm{~mm}$ root mean square error (RMSE) in ZTD (Emardson et al. 1998). Vienna mapping function (VMF) has been used to map the ZTD line of sight along the zenith direction (Boehm et al. 2006). The ocean tide loading correction using finite element solution tide model 2004 (FES2004) has been applied during the processing of data (Schmid et al. 2005). The phase-center-variation (PCV) model in the processing improves the precision and accuracy of GNSS derived ellipsoidal heights and ZTD estimation. To avoid the satellite geometry change and multipath effects, an elevation angle of greater than $10^{\circ}$ is selected for all stations. A higher cut off angle $\left(>10^{\circ}\right)$ may introduce dry bias in the PWV estimation (Emardson et al. 1998).

The effect of the troposphere causing delays in GNSS signal propagation is estimated by high-precision geodetic applications. The ZTD is separated into the sum of the dry part (ZHD) and the wet part (ZWD) components as given in the following relation (Thayer 1974):

$$
Z T D=Z H D+Z W D
$$

ZHD can be modelled accurately (RMSE around 0 . $5 \mathrm{~mm})$, using surface pressure $\left(\mathrm{P}_{\mathrm{s}}\right)$. Surface pressure is the atmospheric pressure at a location on surface of the Earth. It is directly proportional to the mass of air over that location. Elgered et al. (1991) assumed that atmosphere is in hydrostatic equilibrium and proposed following model:

$$
Z H D=(2.2779 \pm 0.0024) \frac{P_{s}}{(1-0.00266 \cos 2 \theta-0.000279 H)}
$$

Where $\mathrm{P}_{\mathrm{s}}$ is the surface pressure in (hPa), and $\theta$ is latitude and $\mathrm{H}$ is height (in $\mathrm{km}$ ) of the surface above the ellipsoid. Nilsson and Elgered (2008) noticed an error of 2. $3 \mathrm{~mm}$ in the ZHD, resulting from $1 \mathrm{hPa}$ in $\mathrm{P}_{\mathrm{s}}$, hence in ZWD, which is equivalent to a PWV error of $0.35 \mathrm{~mm}$. $Z W D$ is a function of atmospheric temperature $T$ (in Kelvin), partial pressure $P_{v}$ of water vapor (in mill bar), and the integral along the zenith path; so the delay is given in units of $\mathrm{z}$ with some constants (Davis et al. 1985)

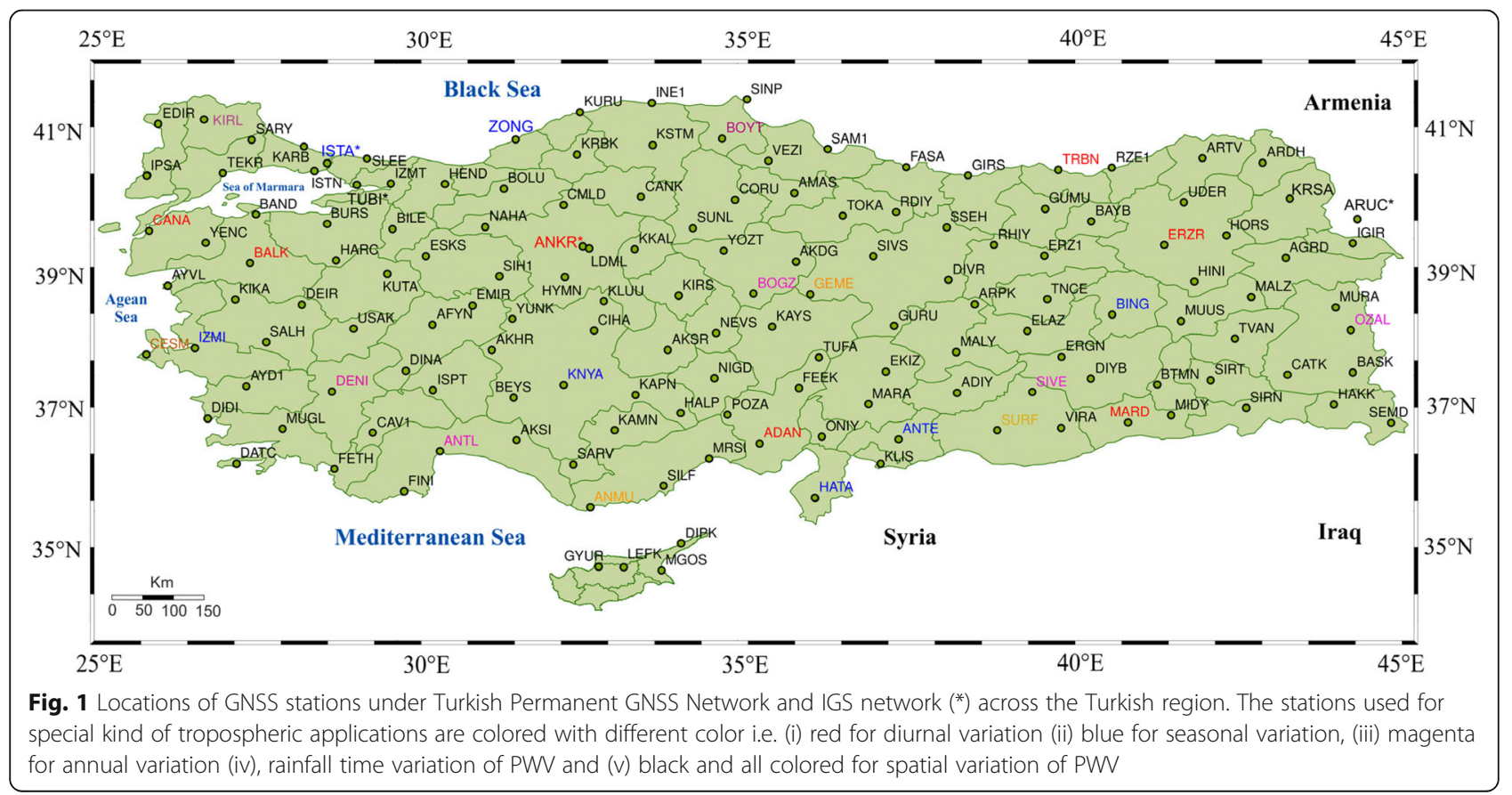


Table 1 Geographical co-ordinate of selected TPGNS and IGS (*) GNSS stations across Turkish region

\begin{tabular}{|c|c|c|c|c|}
\hline GNSS Station & $\begin{array}{l}\text { Geog. } \\
\text { lat. }\left({ }^{(} \mathrm{N}\right)\end{array}$ & Geog. lon. $\left({ }^{\circ} \mathrm{E}\right)$ & Region & GNSS Station used for \\
\hline CANA & 40.11 & 26.41 & Marmara Region & diurnal variation, spatial variation \\
\hline ISTA* $^{*}$ & 41.10 & 29.02 & Marmara Region & seasonal variation, spatial variation \\
\hline KIRL & 41.74 & 27.22 & Marmara Region & annual variation, spatial variation \\
\hline TRBN & 41.01 & 39.71 & Black Sea Region & diurnal variation, spatial variation \\
\hline ZONG & 41.45 & 31.78 & Black Sea Region & seasonal variation, spatial variation \\
\hline BOYT & 41.46 & 34.80 & Black Sea Region & annual variation, spatial variation \\
\hline BALK & 39.64 & 27.89 & Aegean Region & diurnal variation, spatial variation \\
\hline IZMI & 38.39 & 27.08 & Aegean Region & seasonal variation, spatial variation \\
\hline DENI & 37.76 & 29.09 & Aegean Region & annual variation, spatial variation \\
\hline ADAN & 37.00 & 35.34 & Mediterranean Region & diurnal variation, spatial variation \\
\hline HATA & 36.20 & 36.16 & Mediterranean Region & seasonal variation, spatial variation \\
\hline ANTL & 36.89 & 30.67 & Mediterranean Region & annual variation, spatial variation \\
\hline ANKR* & 39.89 & 32.76 & Central Anatolia Region & diurnal variation, spatial variation \\
\hline KNYA & 37.86 & 32.48 & Central Anatolia Region & seasonal variation, spatial variation \\
\hline BOGZ & 39.19 & 35.26 & Central Anatolia Region & annual variation, spatial variation \\
\hline ERZR & 39.91 & 41.26 & Eastern Anatolia Region & diurnal variation, spatial variation \\
\hline BING & 38.89 & 40.50 & Eastern Anatolia Region & seasonal variation, spatial variation \\
\hline OZAL & 38.66 & 43.99 & Eastern Anatolia Region & annual variation, spatial variation \\
\hline MARD & 37.32 & 40.73 & Southeastern Anatolia Region & diurnal variation, spatial variation \\
\hline ANTE & 37.06 & 37.37 & Southeastern Anatolia Region & seasonal variation, spatial variation \\
\hline SIVE & 37.75 & 39.33 & Southeastern Anatolia Region & annual variation, spatial variation \\
\hline CESM & 38.30 & 26.37 & Western Turkey & rainfall variation, spatial variation \\
\hline ANMU & 36.07 & 32.87 & South Turkey & rainfall variation, spatial variation \\
\hline GEME & 39.19 & 36.08 & Central Turkey & rainfall variation, spatial variation \\
\hline SURF & 37.19 & 38.82 & Southeastern Turkey & rainfall variation, spatial variation \\
\hline ARUC* & 37.23 & 39.75 & Armenia & spatial variation \\
\hline \multicolumn{3}{|c|}{ Rest 116 Station from Fig. 1} & Turkey and Northern Cyprus & spatial variation only \\
\hline
\end{tabular}

$$
Z W D=10^{-6}\left[c_{1}\left(\frac{P_{v}}{T}\right) d z+c_{2} \int\left(\frac{P_{v}}{T^{2}}\right) d z\right]
$$

Where $\mathrm{c}_{1}=17 \pm 10 \mathrm{Kmbar}^{-1}$ and $\mathrm{c}_{2}=10^{5}(3.776 \pm 0.004)$ $\mathrm{K}^{2} \operatorname{mbar}^{-1}$.

The PWV of the atmosphere is defined as the height of an equivalent column of liquid water and is almost proportional to ZWD (Bevis et al. 1992):

$$
\begin{aligned}
P W V & =k . Z W D \text { with } k \\
& =10^{-6}\left[10^{-6}\left(c_{2} / T_{m}+c_{1}\right) R_{v} \rho\right]^{-1}, k \approx 0.15
\end{aligned}
$$

Where $R_{v}$ is the gas constant, and $T_{m}$ is the temperature of water vapor and can be expressed in terms of surface temperature $\left(T_{s}\right)$ (Bevis et al. 1992). The surface temperature $(T s)$ indicates how hot the surface of the Earth would feel to the touch in a particular location. From a satellite's point of view, the surface is whatever it sees when it looks through the atmosphere to the ground. It could be snow and ice, the grass on a lawn, the roof of a building.

$$
T_{m} \approx 70.2+0.72 T_{s}
$$

Wang et al. (2005) suggested that the best option to estimate $T_{m}$ in the absence of humidity and local atmospheric temperature is to calculate it using atmospheric reanalysis. They used ERA-40 humidity and temperature data with adjustment to GNSS station heights and observation times. In the present study, the PWV variation at different time scales is 
carried out by using Eq. (7). The reanalysis of PWV datasets is estimated by using basic rule of statics for discrete data:

$$
T_{m}=\frac{\int \frac{P_{v}}{T} d z}{\int \frac{P_{v}}{T^{2}} d z} \quad \approx \quad \frac{\sum_{i=1}^{n} \frac{P_{v i}}{T_{i}} \Delta z_{i}}{\sum_{i=1}^{n} \frac{P_{v i}}{T_{i}^{2}} \Delta z_{i}}
$$

The $\Delta \mathrm{Z}$ is the difference of geo-potential heights of two consecutive pressure levels. The summations are carried out for each pressure levels (37 levels) of the reanalysis dataset.

The percentage variation of seasonal values has been calculated between maximum and minimum values of PWV by using following formula:

$$
\operatorname{Var}(\%)=\left(\frac{P W V_{\max }-P W V_{\min }}{P W V_{\max }}\right) \times 100
$$

Where, $P W V_{\max }$ and $P W V_{\text {min }}$ refer to the maximum and minimum GNSS-PWV values. The percentage deviation between the GNSS-PWV values and ERA-Interim model has been calculated by Eq. (10) (Ansari et al. 2017b):

$$
\operatorname{Dev}(\%)=\left(\frac{\text { GNSS }_{P W V}-\text { Model }_{P W V}}{G N S S_{P W V}}\right) \times 100
$$

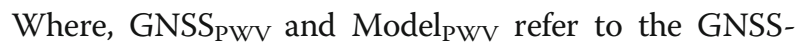
PWV and PWV from ERA-Interim and ARMA model values. Further, the root mean square error (RMSE) values are estimated between the GNSS $_{\mathrm{PWV}}$ and Model $_{\mathrm{PWV}}$ as follows:

$$
R M S E=\sqrt{\sum_{P W V=1}^{N} \frac{1}{N}\left(\text { GNSS }_{P W V}-\text { Model }_{P W V}\right)^{2}}
$$

Where $N$ stands for the number of observation.

The tropospheric variability of PWV around the monthly median values has been checked by using the formula of relative deviation. The relative deviation estimates the monthly and yearly variations of the PWV using Eq. (12) given by:

$$
P W V_{\text {Rel }}=\frac{P W V_{\mathrm{M}}-P W V_{Y}}{P W V_{Y}}
$$

Where, $P W V_{M}$ and $P W V_{Y}$ represent the respective monthly and the yearly median value of PWV. The $P W V_{\text {Rel }}$ denotes the PWV relative deviation. The grand PWV variation is then examined to recognize the PWV variation and the corresponding forecast made by ERAInterim and ARMA models by using following equation:

$$
\begin{aligned}
& P W V_{\text {grand-mean }}=\frac{1}{n_{\mathrm{M}} n_{\mathrm{Y}}} \sum_{n_{\mathrm{M}}=1}^{n_{\mathrm{M}}} \sum_{n_{\mathrm{Y}}=1}^{n_{\mathrm{Y}}} P W V_{n_{\mathrm{M}} n_{\mathrm{Y}}} \\
& P W V_{\text {grand-intensity }}=\sqrt{\frac{1}{n_{\mathrm{M}} n_{\mathrm{Y}}}\left[\sum_{n_{\mathrm{M}}=1}^{n_{\mathrm{M}}} \sum_{n_{\mathrm{Y}}=1}^{n_{\mathrm{Y}}}\left(P W V_{n_{\mathrm{M}} n_{\mathrm{Y}}}-P W V_{\text {ave }}\right)^{2}\right]}
\end{aligned}
$$

Where, the PWV grand-mean represents the yearly grandmean, $\mathrm{PWV}_{\text {grand-intensity }}$ is the yearly grand-variation

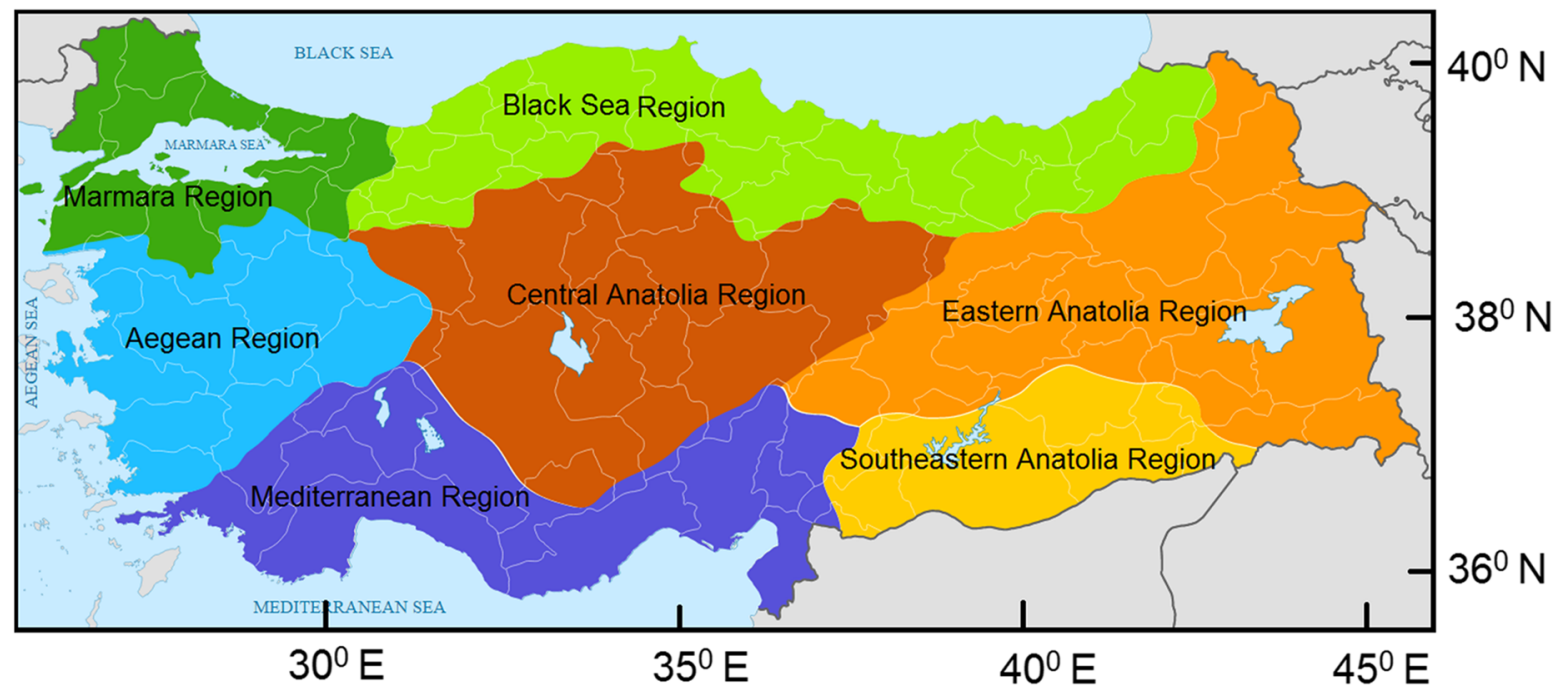

Fig. 2 The seven official geographical regions of Turkey i.e. the Black Sea Region (light green), the Marmara Region (dark green), the Aegean Region (blue), the Central Anatolia Region (brown), Mediterranean Region (purple), the Southeastern Anatolia Region (yellow) and the Eastern Anatolia Region (orange) 
intensity and $\mathrm{PWV}_{\text {ave }}$ is the yearly average value of the PWV. The numeric number $n_{M}$ and $n_{Y}$ symbolize the number of PWV records per month and per year respectively.

\section{Study area}

The geographical regions of Turkey were originally classified into seven regions (bölge) by the first Turkish geography congress in 1941. These seven regions are sub classified into 21 sections (bölüm). These sections are further divide into several areas (yöre) based on local geographic formations and microclimate boundaries. The seven official geographical regions as shown in Fig. 2 are the Black Sea Region (light green), the Marmara Region (dark green), the Aegean Region (blue), the Central Anatolia Region (brown), Mediterranean Region (purple), the Southeastern Anatolia Region (yellow) and the Eastern Anatolia Region (orange). The Marmara Region is belonging to the northwestern Turkey. It has a humid subtropical climate or hybrid Mediterranean climate on the south Marmara Sea coast and the Aegean Sea coast in the western side, a humid continental climate in the interior and an oceanic climate on the Black Sea coast towards east. The Black Sea Region is belonging to the north of Turkey is bordered by the Black Sea to the north. The region has heavy and evenly distributed rainfall in a yearly round with an oceanic climate. The Black Sea coast receives the highest $(\sim 2500 \mathrm{~mm})$ yearly precipitation in Turkey. The Aegean Region located in western Turkey having the longest coastline favoring moisture advection from the sea breeze. The region has a semi-arid continental climate in the interior and Mediterranean climate at the coast. The Mediterranean Region located in southwest Turkey containing chains of mountains. It has a semi-arid continental climate in the interior and Mediterranean climate at the coast. The Central Anatolia Region is located in centre of Turkey having a semi-arid continental climate. Most of the area from the Central Anatolia Region generally receives low precipitation all over the year. The Eastern Anatolia Region is belonging to the easternmost part of Turkey is bordered by Black Sea Region to the north. This region has a harsh continental climate. The Southeastern Anatolia Region is located southeast of Turkey has and holds a semi-arid continental climate.

We selected four IGS and 138 TPGN station to investigate PWV variation all over the country based on these regions (Table 1). As per our information, there are barely any studies on PWV and model presentation over entire Turkish territory with diverse datasets. Hence we hope the study will be helpful for additional understanding of tropospheric dynamics over the whole Turkish region and improved the existing tropospheric models for better prediction.

\section{Results and discussions}

Here, we investigated the behavior of PWV variations estimated from GNSS stations in terms of diurnal, seasonal, annual and as well as spatial domain. The variations of GNSS PWV are compared with those from ERA-Interim using interpolated pressure and temperature dataset and the ARMA forecasting model. Also, we used TRMM, 3A12 version 7 rainfall data to investigate the variation in rainfall pattern and its relationship with PWV over the Turkish territory.

\section{Diurnal variation of PWV}

The diurnal variability of water vapor over a region depends on interactions between the evaporation at the earth surface, atmospheric large-scale horizontal motion, moisture convergence from sea breeze circulation and

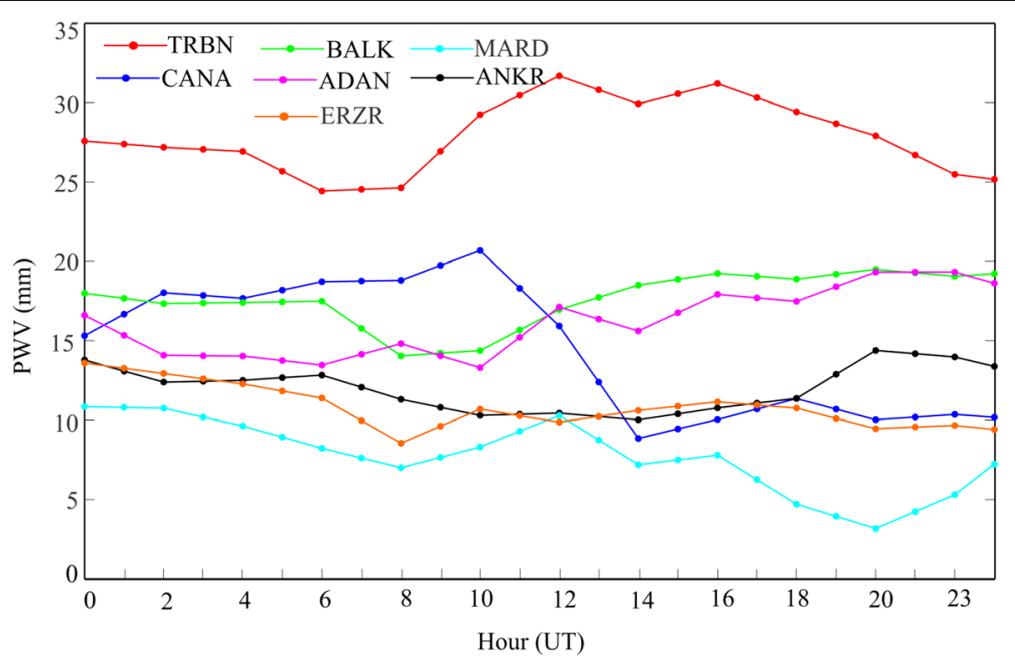

Fig. 3 The diurnal variations of GNSS-PW across the Turkish region on randomly selected day (19 July 2015) 
precipitation as well as vertical mixing (Dai et al. 2002). In the present study, the PWV dependence on geographical location and season is explored to understand its daily variations over Turkish region. Figure 3 shows diurnal variation of PWV on 19 July 2015 (a randomly selected day from summer season) over seven distributed sites, namely TRBN, CANA, BALK, ADAN, ERZR, MARD and ANKR across the region. The figure shows that the PWV has normal variation at early times, attains a peak approximately around 12:00 UT and later retains its normal value till the midnight confirming the controlling temperature factor. The evaporation by diurnal warming increases the precipitable water vapor content in the atmosphere. A correlation (0.5 to 0.2) between PWV and temperature was observed with the highest correlation seen in the Black sea region and the lowest in the Aegean region (Ansari et al. 2016). Another important factor, wind is enabling evaporation in the lower layers of atmosphere close the ground level and works like the conveyor belt of moisture. The average value of the diurnal PWV at all stations except TRBN is almost the same. It is clear from the Fig. 3 that the diurnal cycle of PWV is maximum at TRBN, located in the Black sea region. The region has an oceanic climate with high and evenly distributed rainfall over the year. The region is greatly influenced by moisture advection from breezing of sea which is the cause of the continuously increment of PWV even after the air temperature decreased (Ortiz de Galisteo et al. 2011). The TRBN has lower PWV value at
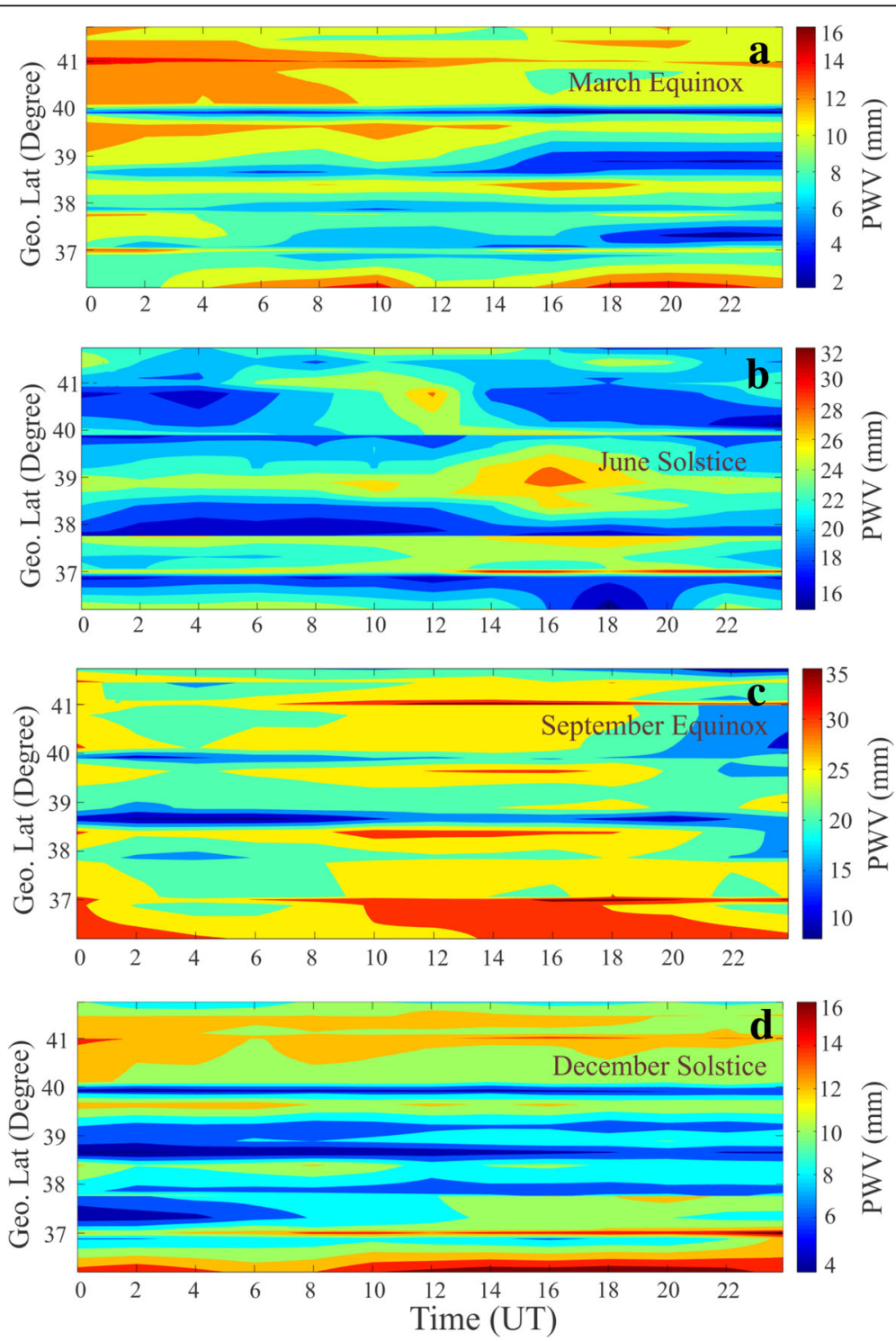

Fig. 4 The diurnal color contour plots of VTEC over Turkish region during a March equinox, b June solstice, c September equinox and d December solstice of the year 2016 
nighttime and it increases during the day because of the fast cooling of the land causing the breeze regime at night and in reverse blowing from land to sea during the day. The GNSS station MARD showing lowest PWV value is located in the Southeastern Anatolia Region. This region entirely belongs to the continental area and has a semi-arid continental climate. The station has lower value after 16.00 UT till midnight. The cooling of weather at this time is the reason of the PWV decrement by condensation.

The diurnal PWV contour plots at March and September equinoxes, June and December solstices of the year 2016 are shown in Fig. 4. The diurnal variation of PWV cycle varies from time to time and season to season. The comparison graphs of the seasonal diurnal cycles show that the PWV cycle is clearly stronger in summer than in any other season. The region has distinct diurnal PWV pattern in each season with maximum value (10-35) $\mathrm{mm}$ in June solstice and minimum in March equinox (2-16) $\mathrm{mm}$. The PWV in December solstice is varying from 4 to $16 \mathrm{~mm}$ while in June solstice is varying from 10 to $35 \mathrm{~mm}$. It means that the differences between PWV effects are lowest in winter, while in summer it has larger dispersion. The variation of PWV cycle in winter is quite similar at all places in spite of their geographical locations. However, in summer the strong local effects makes the diurnal cycle quite different among the stations. In March equinox, the sub daily variability from 2 to $16 \mathrm{~mm}$ is slightly larger than those of winter while the September equinox has the greatest variability ranging from 10 to $35 \mathrm{~mm}$. It is because the dispersion increases in spring time, and even more in autumn time. However, at some locations autumn and spring show transitional form between summer and winter in the vicinity of the Black sea region coast while the others are similar to the winter cycle (Ortiz de Galisteo et al. 2011).

\section{Seasonal variation of PWV}

In the present study, the whole year is categorized into four seasons to investigate the seasonal variations i.e., December solstice which includes the months of November, December, and January (NDJ), March equinox consisting of February, March, and April (FMA), June solstice comprising May, June, and July (MJJ) and September equinox that involves August, September, and October (ASO) months. We analyze the seasonal behavior of GNSS PWV changes of the year 2009, 2012 and 2016 over the seven stations namely ISTA, ZONG, IZMI, HATA, KNYA, BING and ANTE sited in seven different regions of Turkey. The average seasonal variation of PWV at the selected stations is shown in Fig. 5. The PWV has a seasonal behavior with the maximum in June solstice and September equinox and the minimum in December solstice and March equinox. The maximum average values reach around $30 \mathrm{~mm}$ and minimum average values around $6 \mathrm{~mm}$. During the summer months, the increase in temperature accompanied by an increase in evaporation from the ground causes water vapor to concentrate in the atmospheric layers consequently increasing the PWV. In winter months, the low temperature reduces the evaporation and facilitates the increased condensation resulting in a reduction in the PWV. Additionally, during warm periods, increases in the temperature and height of constant-pressure levels result in an increased capacity for water vapor of the air mass, keeping it away from the saturation point and thereby preserving high PWV values (Campmany et al. 2010). In contrast, in cold periods, the decrease in the height of constant-pressure levels reduces the capacity for water vapor of the air mass and facilitates the condensation process, resulting in a decrease in the amount of PWV. The percentage variation between the

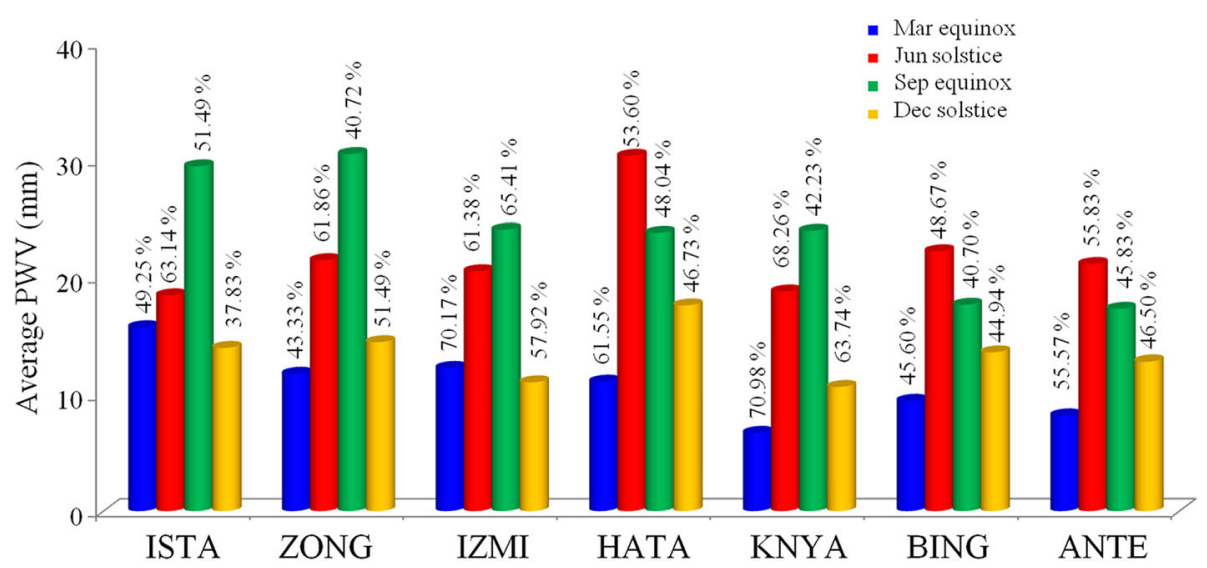

Fig. 5 Seasonal variations of GNSS-PW of average value of the years 2009, 2012 and 2016 over the seven stations namely ISTA, ZONG, IZMI, HATA, KNYA, BING and ANTE. The above values with percentage (\%) symbol show the percentage variation between the maximum and the minimum values 
maximum and the minimum values which has been calculated by Eq. (9) for each of the selected stations is different which is possibly attributable to the variation of the atmospheric humidity and temperature ( $\mathrm{Li}$ et al. 2015). Peixoto et al. (1981) noticed that the level of water vapor contrasted between winter and summer but this pattern is not followed in autumn and spring. Unlikely, the present results over the Turkish region show that the PWV is constrained in every season; some locations have higher value in September equinox and some of them have it in June solstice. The variation of PWV is related not only to the seasonal variation but also to the topographic features and local characteristics (Wang et al. 2013). The PWV has higher average value, i.e., $\sim 30 \mathrm{~mm}$ (ISTA), $\sim 31 \mathrm{~mm}$ (ZONG), $\sim 25 \mathrm{~mm}$ (IZMI) and $\sim 25 \mathrm{~mm}$ (KNYA) in September equinox while the eastern stations show higher value as $\sim 30 \mathrm{~mm}$ (HATA), $23 \mathrm{~mm}$ (BING) and $\sim 21 \mathrm{~mm}$ (ANTE) during June solstice. The water vapor sources in western region are mainly from the Marmara, Black Sea, Aegean and Mediterranean Sea. The meridional wind is an important cause of PWV content in the atmosphere from these seas. If the component of zonal wind will strong, it will restrict the growth of the component of meridional wind which causes the PWV decrement in these regions. The change of the zonal and meridional wind strengths brings the repeated changes in water vapor. On the other hand, in June solstice, the monsoon system influence the Eastern part of Turkey and the prevailing southerly wind brings large amount of water vapor to the mainland of the country. In winter, the wind brings in cold and dry air resulting lower PWV in December solstice i.e., $\sim 15 \mathrm{~mm}$ (ISTA) and $\sim 10 \mathrm{~mm}$ (IZMI) and in late March equinox i.e., $\sim 12 \mathrm{~mm}$ (ZONG), $\sim 11 \mathrm{~mm}$ (HATA), $\sim 6 \mathrm{~mm}$ (KNYA), $\sim 8 \mathrm{~mm}$ (BING), and $\sim 7 \mathrm{~mm}$ (ANTE) influenced by the Asian monsoon system. Combining the two points, we can conclude that the variation of the GNSS PWV content in atmosphere is related to strength of change in wind component and to the Asian monsoon system (Wang et al. 2013).

We calculated the deviation between GNSS vs ERA Interim PWV and GNSS vs ARMA PWV models by using Eq. (10). The variation of PWV effect obtained from GNSS stations are also compared with their corresponding PWV values from ERA-Interim and ARMA models (Fig. 6). The values derived from ERA-Interim model depict bias deviations in comparison to ARMA model at all sites. The percentage deviation of GNSS vs ARMA model is low. It means that our modeling using the local data is perfect than the ERA-Interim global model. The negative and positive percentage deviations demonstrate the overestimation and underestimation of observed GNSS PWV respectively. The ERA-Interim model is generally underestimating the GNSS-PWV all the time at the BING, ZONG and IZMI stations while ANTE station shows overestimating characteristics. Moreover, the underestimation of ERA-Interim model is extended up to $~ 35 \%$ over BING in January and March, followed by October and December whereas over ZONG in July and September. The station KNYA and ISTA show

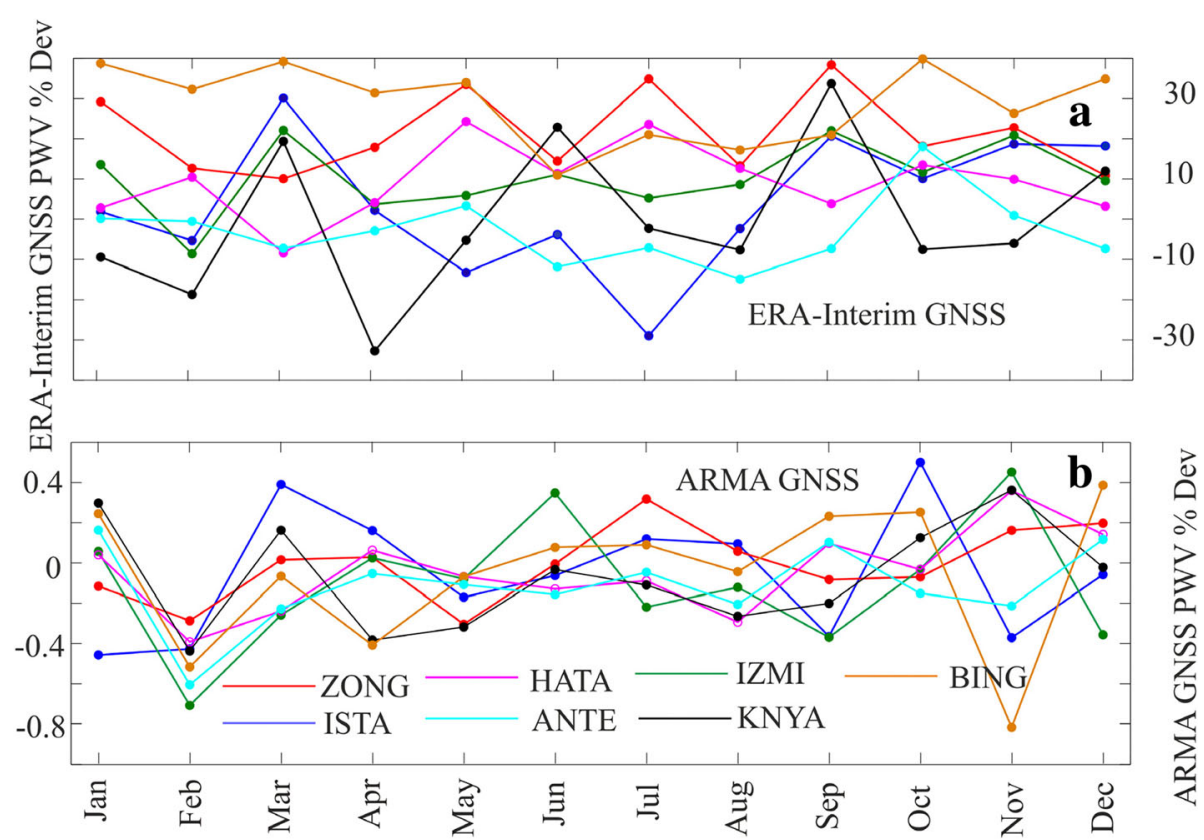

Fig. 6 The monthly percentage of deviation between the a ERA-Interim, b ARMA model predicted PWV and observed GNSS-PWV over ISTA, ZONG, IZMI, HATA, KNYA, BING and ANTE of average values of the years 2009, 2012 and 2016 
the lowest deviation $(\sim 30 \%)$ in April and July respectively (Fig. 6a). The GNSS geographical coordinate and ERAInterim grid point are closely related but the bias percentage deviations from ERA-Interim models could be due to the height difference between grid point and GNSS sites (Yeh et al. 2016). When the percentage deviation value of ERA Interim derived PWV is compared to ARMA model over the Turkish region, it indicates the necessity of further accuracy improvements of the ERA-Interim datasets.

The RMSE values are calculated between GNSS PWV vs ERA-Interim PWV and GNSS PWV vs ARMA PWV values by using Eq. (11). These kinds of individual differences are used as residuals and to measure the prediction errors. The RMSE values of PWV variations with ERA-Interim model and ARMA model to observed GNSS PWV over seven sites are shown in Fig. 7. It can be noticed from the figure that the ERAInterim model shows $\sim 4 \mathrm{~mm}$ RMSE over all station except $\sim 11 \mathrm{~mm}$ over ZONG. The ZONG station is located in the Black sea region. However, ERA-Interim has less RMSE magnitudes $(\sim 2 \mathrm{~mm})$ at ANTE than others. This could be due to the less disturbed GNSS observed data at ANTE. The station is located in Southeastern Anatolia Region which entirely belongs to the continental area and has a semi-arid continental climate.

\section{Annual variation of PWV}

The PWV annual variation is studied to understand the local and temporal behavior of PWV over Turkish region. The annual PWV from the January 2009 to April
2017 at seven different stations i.e. KIRL, BOYT, DENI, ANTL, BOGZ, OZAL and SIVE, representing the official regions of Turkey are shown in respective figures Fig. $8 \mathrm{a}$ to $8 \mathrm{~g}$. It is clear from the figures that the range of PWV in Turkey is between 0 to $45 \mathrm{~mm}$. The PWV values at stations located closer to the coastal part of Turkey, for example, KIRL, BOYT, and ANTL show larger variation because of warm air holds more moisture and cold air is drier in these regions. The variation and magnitude of PWV are typically less at BOGZ, OZAL and SIVE. This is because these sites are situated in the continental inland which generally have less PWV annual variation than the coastal sites. The maximum yearly diurnal peak value of $\sim 40 \mathrm{~mm}$ at KIRL in 2010 and 2012, BOYT in 2009, 2010 and 2015 and DENI in 2015, $45 \mathrm{~mm}$ at ANTL in 2015, $30 \mathrm{~mm}$ at OZAL in 2012 and $\sim 33 \mathrm{~mm}$ at SIVE in 2010 are observed during the year 2009 to 2017. The selected seven GNSS sites sample quite different climate conditions across the country. The fact that the annual variation of PWV cannot be attributed solely to the location (coast and continent) but also to the importance of other direct factors such as thermodynamic and hydrological causes or indirect factors such as solar activity (Maghrabi and $\mathrm{Al}$ Dajani 2014). Exploring the direct or indirect causes of the annual variation of the PWV is beyond the limitations in tour study due to unavailability of adequate multi-platform data sources and comprehensive information. The time series of the nine-year PWV estimation depict strong annual variation in PWV at all sites,

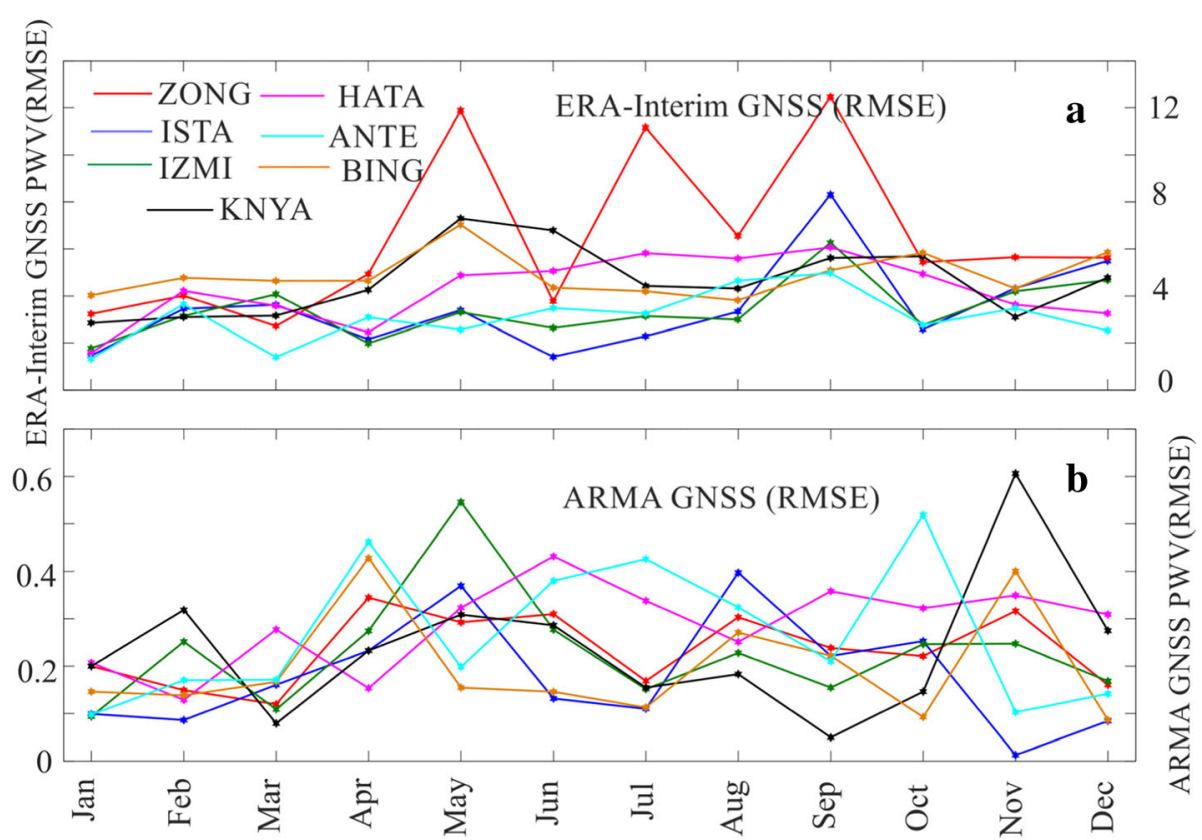

Fig. 7 The monthly RMSE values between the a ERA-Interim, b ARMA model predicted PWV and observed GNSS-PWV over ISTA, ZONG, IZMI, HATA, KNYA, BING and ANTE of average values of the years 2009, 2012 and 2016 


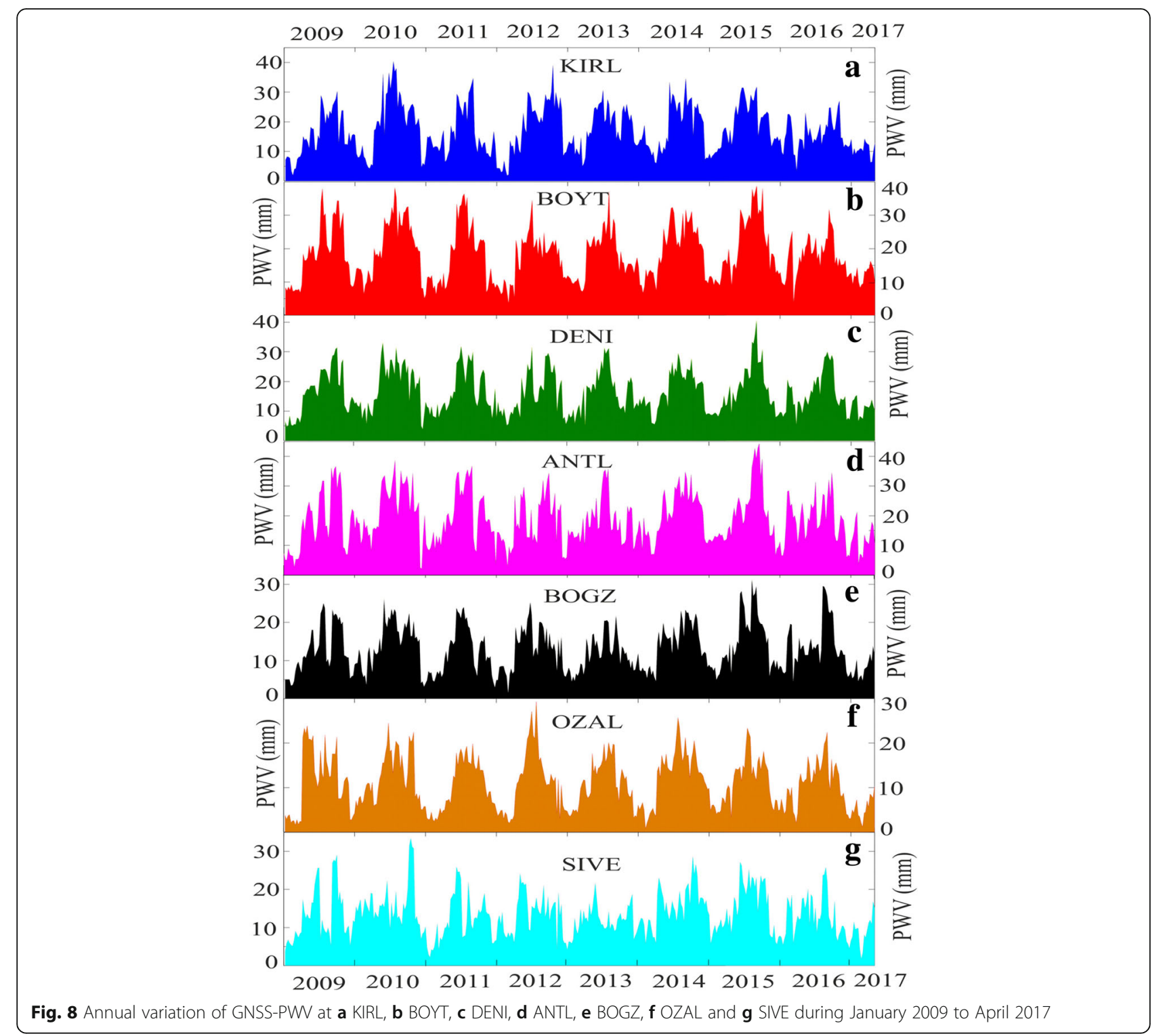

with distinctive peaks and dips occurring approximately at the summer and winter, respectively. We found that during 2009 to 2017 the precipitation depicts an apparent incremental trend in summer but the values are less in winter. The cumulative contributions from the lowlatitude oceans and the west Asian monsoon are the main causes of PWV for the country. In addition to the ocean and monsoon, the Turkish plateau is also a second source of water vapor. The water vapor accumulates in the Turkish plateau and allows entering the water cycle as well movement towards the atmosphere. Because precipitation is much higher in summer, the contribution of the enhanced precipitation is also larger in summer than in other seasons. The overall inference is that the transportation of PWV during the year makes an affirmative role over the plateau whether the weather is summer or winter. The pumping property of Turkish plateau which continuously attracts moist air from low latitude oceans can be another important reason for higher precipitation in summer. Similarly in winter the persistent of anticyclone which occurs over the surrounded Sea along the coast carries PWV into the country.

We calculated the relative deviations of PWV to examine the spatial and temporal variation for the selected sites by using Eq. (12). The yearly relative deviations of PWV for each sites are evaluated with the PWV obtained from the ERA-Interim and ARMA models which indicates the lower and upper quartiles per year value during the period of 2009 to 2017 (Fig. 9). The relative deviations of ERA-Interim predicted PWV values follow the actual observations of GNSS-PWV over the Turkish region but with slight difference in the magnitude. The 


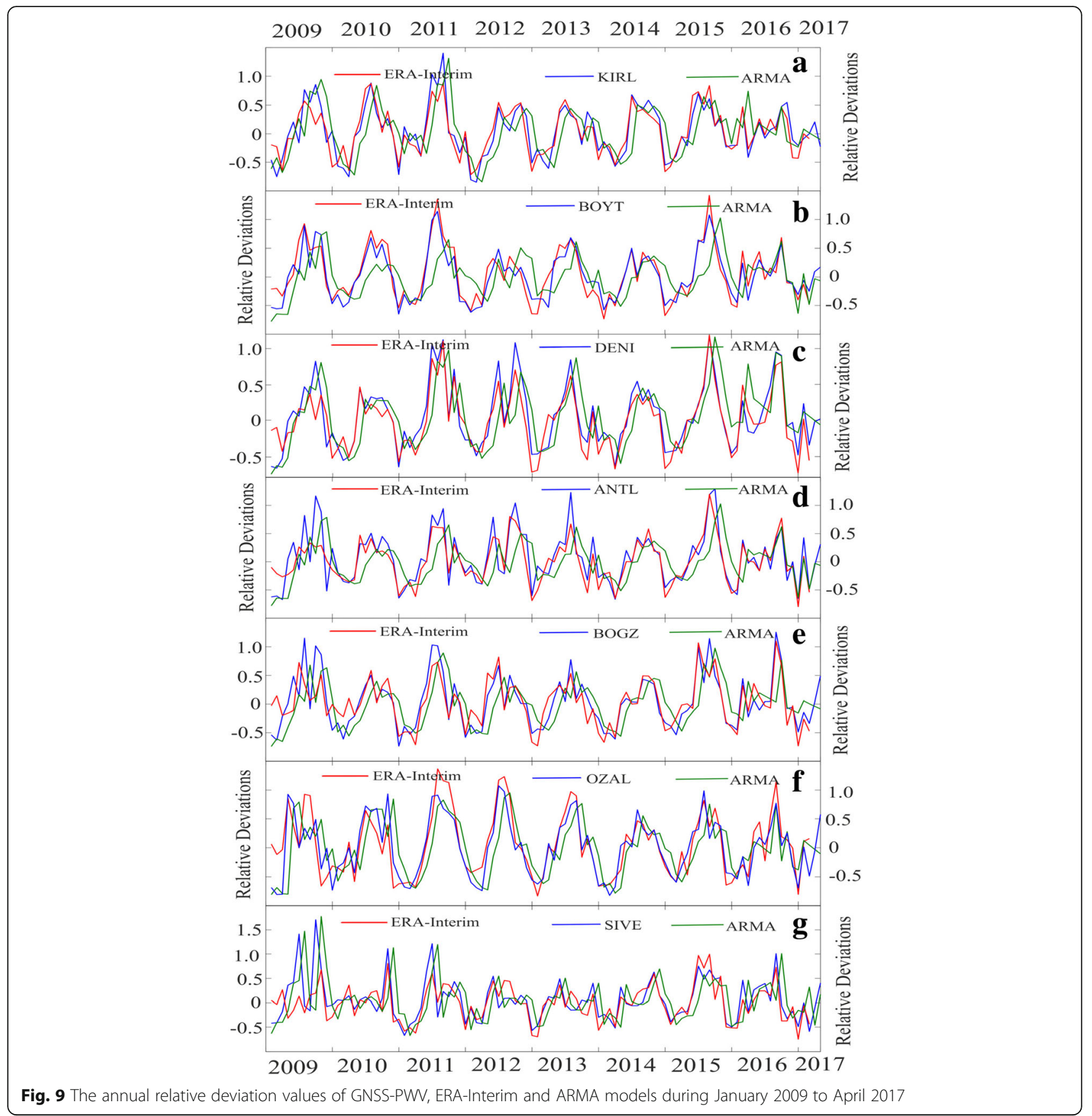

relative tropospheric PWV by the ARMA model is more precise than the ERA-Interim model. The GNSSestimated and ERA-Interim give approximately similar results of PWV at the smooth topographic regions but the ERA-Interim provides slightly different values in rough topographic areas. This difference is mainly connected to the pressure. The deviations between the ERAInterim pressure and measured pressure can increase more in mountainous areas, which affects the ZTD as well as water vapor (Alshawaf et al. 2016). The deviation estimated by the ARMA model is relatively larger than ERA-
Interim during the year of 2010 for the BOYT and ANTL stations, but agrees well at other stations. This is possible due to large variability of GNSS PWV data which cannot be well estimated by ARMA model. The anomaly in variations with negative dips and higher positive peaks can be seen during the period from 2009 to 2017 at all selected sites. The PWV changeability lies in the interval of -0.5 to 1.5 for the selected sites and the range of variation between negative and positive variations is around two. The relative deviation of PWV is highest over SIVE comparison to the other stations during summer of 2009. This is 
probably due to the larger weather variation (hot to hottest) over this region. The growth and reduction of relative PWV deviations are due the physical factor such as temperature, rainfall, humidity, day and night that guides the transfer of PWV. The higher relative deviations are noticed during summer over all stations.

We calculated the annual grand-mean of PWV and compared with ERA-Interim and ARMA models by using Eq. (13). The highest grand-mean of PWV $(\sim 22 \mathrm{~mm})$ is registered in 2010 at ANTL while BOYT has the maximum value $(\sim 21 \mathrm{~mm})$ in 2015 . The lower grand-mean of PWV $(\sim 11 \mathrm{~mm})$ is seen in 2011 and 2015 at OZAL stations (Fig. 10a). The lowest grand-mean value $(\sim 6 \mathrm{~mm})$ is seen in 2017 at OZAL but we cannot consider it as perfect value because in 2017 only four months (January to April) are included in the study. The grand-mean of PWV during 2009 is higher by $22 \mathrm{~mm}$ at ANTL. The values are lowered by $11 \mathrm{~mm}$ in 2011 and by $6 \mathrm{~mm}$ in 2017 at OZAL. The annual grand-mean of ERA-Interim and ARMA models for all stations are showing very good estimation except few month like ARMA model for OZAL in 2016 and ERA-Interim model for BOYT in 2009. It is not surprising because it can happen sometimes due to error or some unexpected variation of data. However the ERAInterim and ARMA models are able to approximate the grand-mean PWV values for all sites during the selected period. The values of the annual grand-mean of PWV and corresponding values of ERA-Interim and ARMA models reproduce the delay in GNSS signal due to water vapor in Turkey. Thus very interesting results are observed from the Fig. 10a that perfect odd-even structures occur during the selected period, the values are declining in odd years (e.g. 2009, 2011, 2013, 2015 and 2017) and ascending in the even digit years (e.g. 2010, 2013, 2014 and 2016) over the Turkish region.

The monthly grand-mean PWV intensity is calculated using Eq. (14) for all selected sites during the years from 2009 to 2017 (Fig. 10b). The GNSS-PWV values of the annual grand-mean PWV intensity and parallel values of ERA-Interim and ARMA models reproduce the water vapor as well as delay in GNSS signal over mid-latitude Turkish region. The highest grand-mean variation of PWV intensity is noticed over the KIRL station in 2010, followed by ANTL in 2009 and 2015. The attribution of the coastal winds that flow from coast sides towards the land parts which holds warm air more moisture and dry
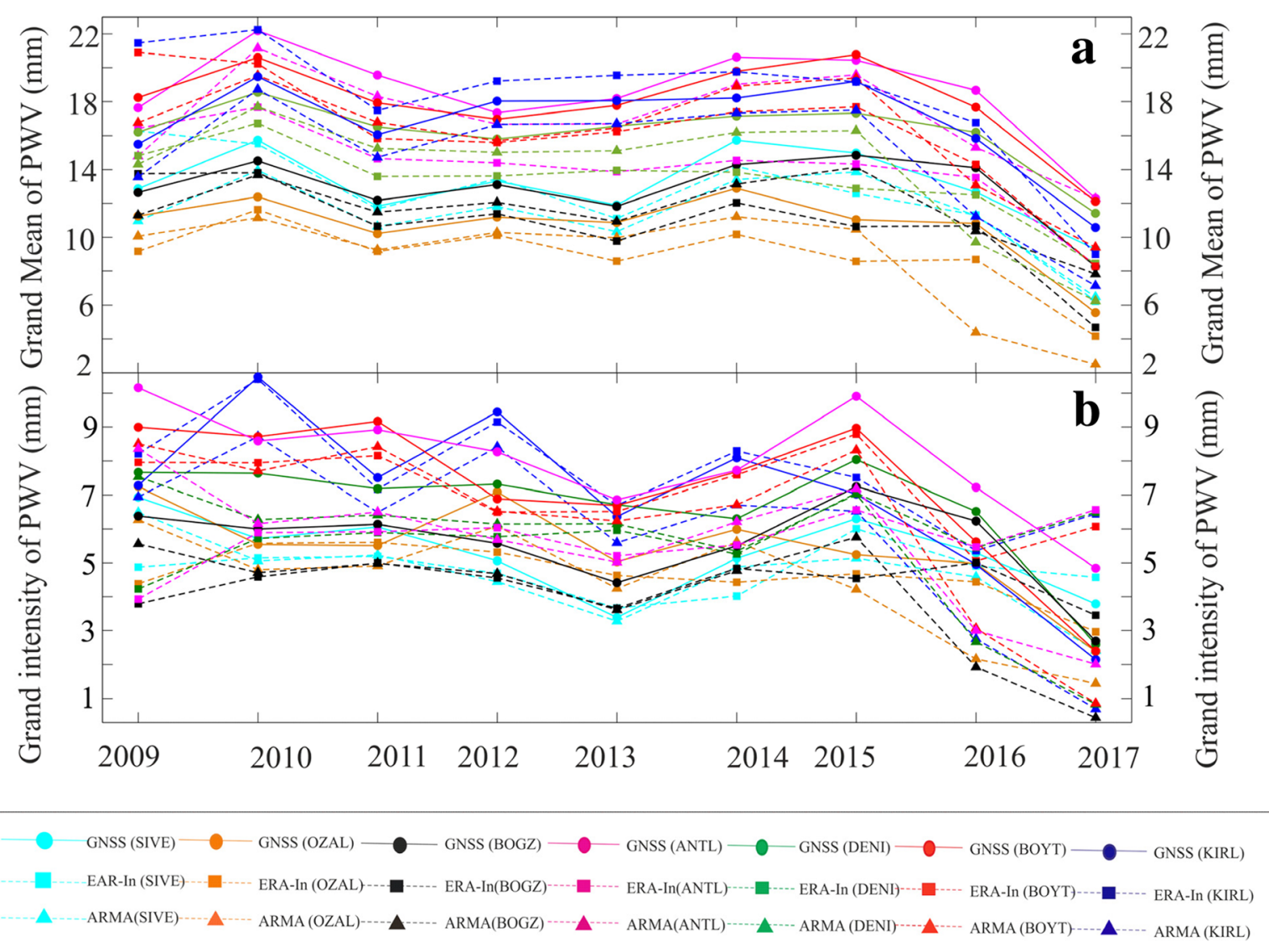

Fig. 10 a The grand-mean of values and $\mathbf{b}$ The grand variation of PWV intensity for annual variations of PWV over Turk during the year from January 2009 to April 2017 
cold air may be the causes of getting maximum grandmean PWV intensity. Generally the measured grandmean intensity variations of PWV values are in climbing phase in 2010, 2012, 2014 and 2015 years while sliding phase in 2013 and 2016 (Fig. 10b). These outcomes show the annual anomaly, which is due to the change in composition of atmospheric constituents. Both models ERA-Interim and ARMA are well-estimating the annual grand PWV intensity variations during the selected year with minimum divergence.

\section{Spatial variation of PWV}

We investigated the spatial variation of PWV over the lower mid-latitude Turkish region on the basis of geographical coordinate (latitude and longitude) and elevation height from sea level. The study involves data from four IGS stations located at Istanbul (ISTA), Gebze (TUBI), Ankara (ANKR) and Armenia (ARUC) and 138 regional stations of Turkish permanent GNSS network (TPGN) (Fig. 1). The scatter plot of PWV variation at six hour interval (00:00 UT, 06:00 UT, 12:00 UT and 18: 00 UT) on 15th of March 2017 (randomly selected day) has been shown in Fig. 11. From this figure, it is clear that the northern boundary of the Turkey, western part of the Country and Northern Cyprus have higher amounts of PWV while the other part of country like Central and Eastern Turkey perceive lower amounts of PWV. Basically, the temporal and spatial variability of water vapor concentration depends on the topography, season and other regional climate conditions
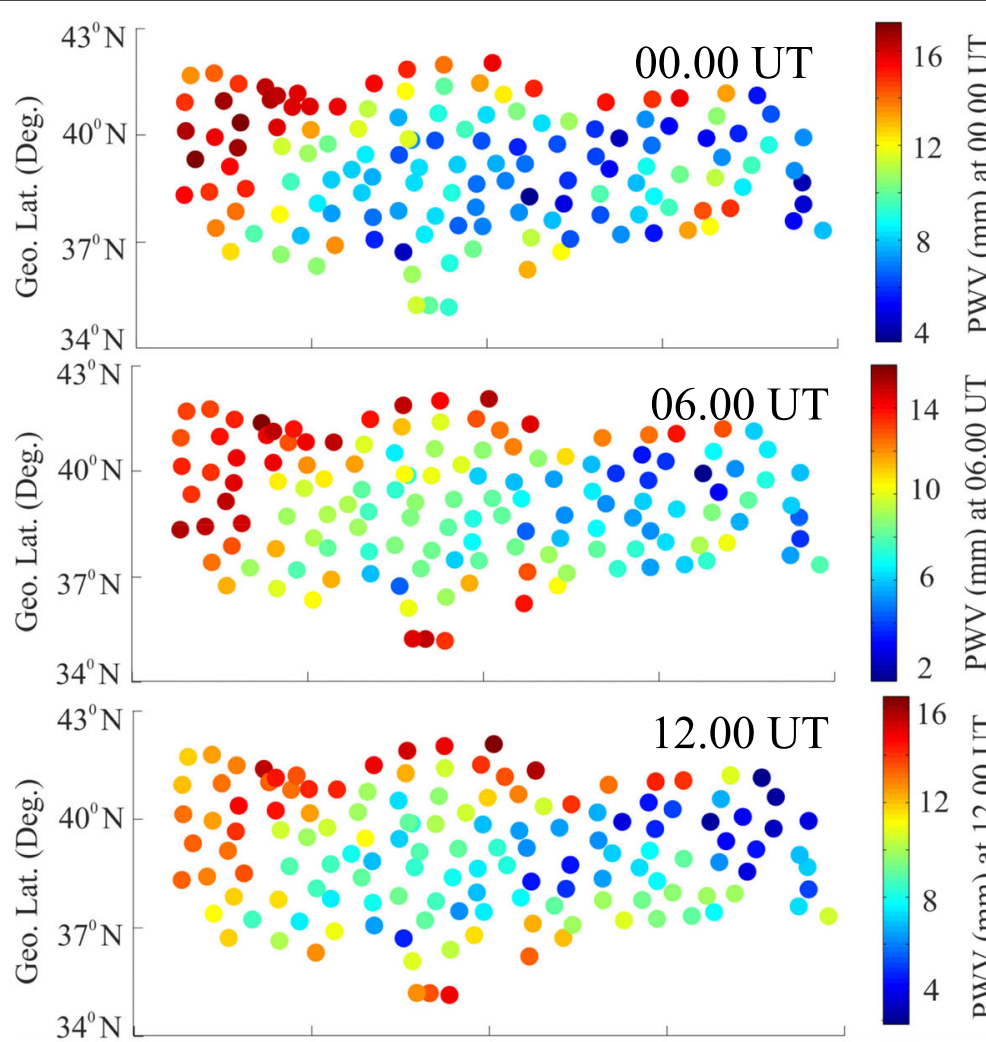

16 官

$12 \stackrel{8}{\mathrm{C}}$

8 齐

可

$4 \sum_{2}$

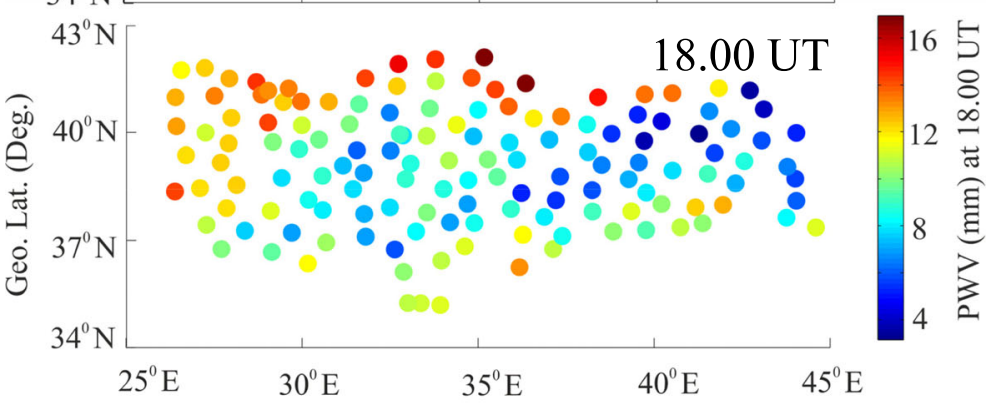

Geo. Long. (Deg.)

Fig. 11 Observed scatter plots of GNSS-PWV variation on randomly selected day (15 March 2017) 
(Choy et al. 2015). Most of the GNSS sites showing higher amount of PWV are located relatively close to the coast of Black sea region and close to the Marmara and Aegean region in western part of the country. The northern Cyprus GNSS sites are situated close to the Mediterranean Sea. These regions have humid subtropical climate or hybrid Mediterranean climate on the south Mediterranean Sea coast and the coast of Aegean Sea, a humid continental climate in the interior and an oceanic climate on the Black Sea coast. The climate of coastal areas keeps the temperatures relatively mild. These stations show considerable variation in PWV amplitude on the basis of that warm air grasps more moisture and the cold air is drier. Most parts of the Eastern Anatolia, Central Anatolia and the Southeastern Anatolia Regions have low precipitation. These regions have continental climate with cold, snowy winters and hot dry summers. The weather remains cool in the highlands and warm in the lowlands.

The PWV variation on the basis of geographical coordinates has been modeled by using an ordinary least square estimator (OLSE) which can estimate the residuals as well. The OLSE residuals are very useful to construct the variance and covariance matrix. The OLSE can represent the variability of the tropospheric process and can be modeled by a polynomial. Let us assume deterministic value of PWV is expressed as a function of the independent variables $(\phi, \lambda$ and $t)$. It is clear from the Fig. 1, that longitude range is more than double the latitude range for covering Turkey. Hence, we used first order function for latitude and second order for longitude to model the PWV (Ansari et al. 2017c).

Let us consider

$$
\begin{aligned}
P W V(\phi, \lambda, t)= & \alpha_{1}(t)+\alpha_{2}(t) \phi+\alpha_{3}(t) \lambda \\
& +\alpha_{4}(t) \lambda^{2}
\end{aligned}
$$

Where $\alpha_{\mathrm{i}}(t)$ are time dependent coefficients.

If the number of observation data is $n$, then by least square approach the polynomial constants of Eq. (15) can be expressed in the following form:

$$
\left[\begin{array}{c}
\Sigma P W V \\
\Sigma P W V \times \phi \\
\Sigma P W V \times \lambda \\
\Sigma P W V \times \lambda^{2}
\end{array}\right]=\left[\begin{array}{cccc}
n & \Sigma \phi & \Sigma \lambda & \Sigma \lambda^{2} \\
\Sigma \phi & \Sigma \phi^{2} & \Sigma \phi \lambda & \Sigma \phi \lambda^{2} \\
\Sigma \lambda & \Sigma \phi \lambda & \Sigma \lambda^{2} & \Sigma \lambda^{3} \\
\Sigma \lambda^{2} & \Sigma \phi \lambda^{2} & \Sigma \lambda^{3} & \Sigma \lambda^{4}
\end{array}\right]\left[\begin{array}{c}
\alpha_{1} \\
\alpha_{2} \\
\alpha_{3} \\
\alpha_{4}
\end{array}\right]
$$

After calculating polynomial constants $\left(\alpha_{\mathrm{i}}\right)$, we can easily model the value of PWV.

We estimated large-scale spatial variation behavior of PWV from GNSS stations during March 2017. The deterministic value of PWV for TPGN network at six hours interval on 15th of March 2017 is modeled as:

$$
\begin{aligned}
P W V(\phi, \lambda, t)= & 47.0126+0.6297 \phi-3.2075 \lambda+0.0405 \lambda^{2} \\
& \text { at } 00.00 U T \\
P W V(\phi, \lambda, t)= & 25.1353+0.3903 \phi-1.3608 \lambda+0.0132 \lambda^{2} \\
& \text { at } 06.00 U T \\
P W V(\phi, \lambda, t)= & 03.6094+0.3421 \phi-0.0554 \lambda-0.0044 \lambda^{2} \\
& \text { at } 12.00 U T \\
P W V(\phi, \lambda, t)= & -0.4184+0.4393 \phi-0.1678 \lambda-0.0010 \lambda^{2} \\
& \text { at } 18.00 U T
\end{aligned}
$$

The output of this model for PWV values are represented at every five degree interval in latitude and every two degree interval in longitude as shown in Fig. 12. The figure clearly shows the decreasing variation of PWV values from northwest corner to southeast corner with respect to geographical coordinate. This is because the eastward longitudes experienced continental climate more time than those of the western longitudes. It is noticed from the figures that the PWV at 00.00 UT and 06.00 UT shows convex variation while the PWV at $12.00 \mathrm{UT}$ and $18.00 \mathrm{UT}$ indicates concave variation. We can easily understand the reason from the derived Eq. 17 that the high constant values as 47.0126 and 25.1353 are at $00.00 \mathrm{UT}$ and 06.00 UT respectively while the low constant values as 3.6094 and -0.4184 are at $12.00 \mathrm{UT}$ and $18.00 \mathrm{UT}$ respectively. This means the PWV variation at night (00.00 UT) and early morning (06.00 UT) have large variations which do not depend upon the geographical coordinate but on the regional factors such as climate and humidity. Besides this, the PWV during the midday (12.00 UT) and early evening (18.00 UT) has less variation and can be modeled in terms of geographical coordinate.

The variation of PWV values is negatively correlated with altitude which has been earlier confirmed by several authors over diverse geographical locations (Wang et al. 2013; Liu et al. 2015). We estimated the variability of PWV with respect to altitude from mean sea level and calculated the best fit line at six hour interval in a day. Our observations also agree with previous researchers showing negative correlation between the mean sea level (MSL) altitude of the terrain and the corresponding PWV (Fig. 13). With increased altitude, PWV value decreases due to lower surface temperature at high altitudes. Also, as the altitude increases, the depth of atmospheric column decreases and accordingly PWV decreases (Jin et al. 2009). The atmospheric pressure varies with the increase in elevation. The mass of the air is affected by the general atmospheric pressure within the mass, creating areas of low pressure (depressions) and high pressure (anticyclones). The high pressure regions have more atmospheric mass above their locations 

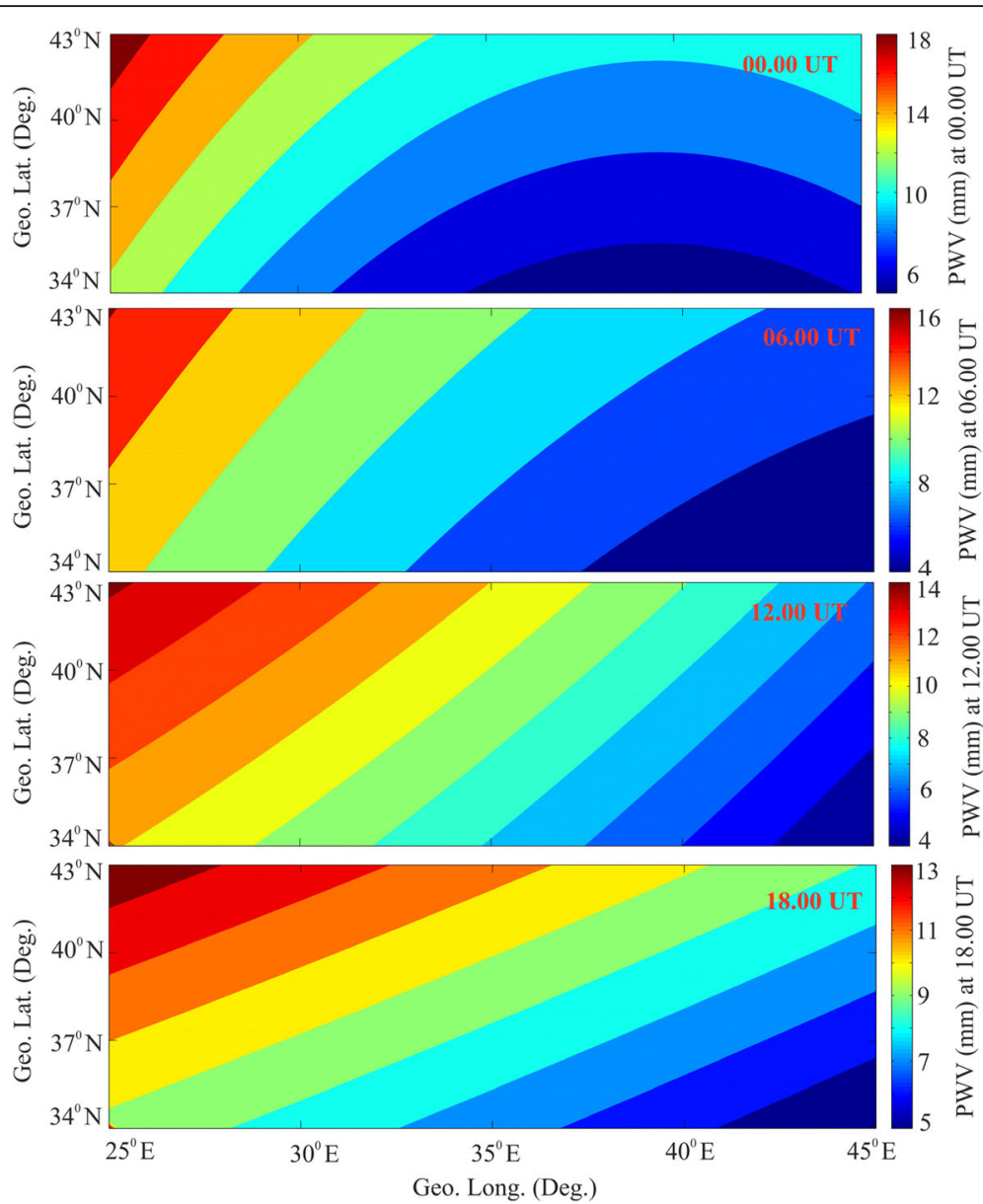

Fig. 12 Modelled contour plots of GNSS-PW variation by OLSE method on randomly selected day (15 March 2017)

whereas the low pressure regions have less atmospheric mass above their locations. There is exponentially less air as the elevation increases. Therefore, atmospheric pressure decreases with increase in altitude. The following formula is a first-order approximation for the relationship between pressure and altitude (Jin et al. 2007):

$$
\log _{10} p \approx 5-\frac{h}{15.5}
$$

Where $p$ is the pressure in Pascal $(\mathrm{Pa})$ and $h$ is the height in millimeters.

The ZHD has direct relation with pressure $p$ at height $h$ (Davis et al. 1985)

$$
Z H D=v p
$$

Where $v$ is a constant equivalent to $2.28 \mathrm{~mm} / \mathrm{Pa}$ (Davis et al. 1985)

Now from Eq. (18) and (19) we can write

$$
\left.Z H D=2.28^{*} 10^{(5-h / 15.5}\right)
$$

Since ZHD is the $90 \%$ part of ZTD and remaining 10\% is ZWD then

$$
\begin{gathered}
Z T D=2.28^{*} 10^{(5-h / 15.5)} \times\left(\frac{100}{90}\right) \\
Z T D=2.533^{*} 10^{(5-h / 15.5)}
\end{gathered}
$$

We can easily estimate 10\% ZWD from ZTD

$$
\begin{gathered}
Z W D=2.533^{*} 10^{(5-h / 15.5)} \times\left(\frac{10}{100}\right) \\
Z W D=0.2533^{*} 10^{(5-h / 15.5)}
\end{gathered}
$$

From Eq. (6), PWV is related to ZWD

$$
\mathrm{PWV} \approx 0.15^{*} \mathrm{ZWD}
$$

Hence from Eqs. (22) and (23)

$$
P W V \approx 0.038^{*} 10^{(5-h / 15.5)}
$$

The GNSS PWV time series have been analyzed at locally distributed 138 GNSS sites along with four IGS 


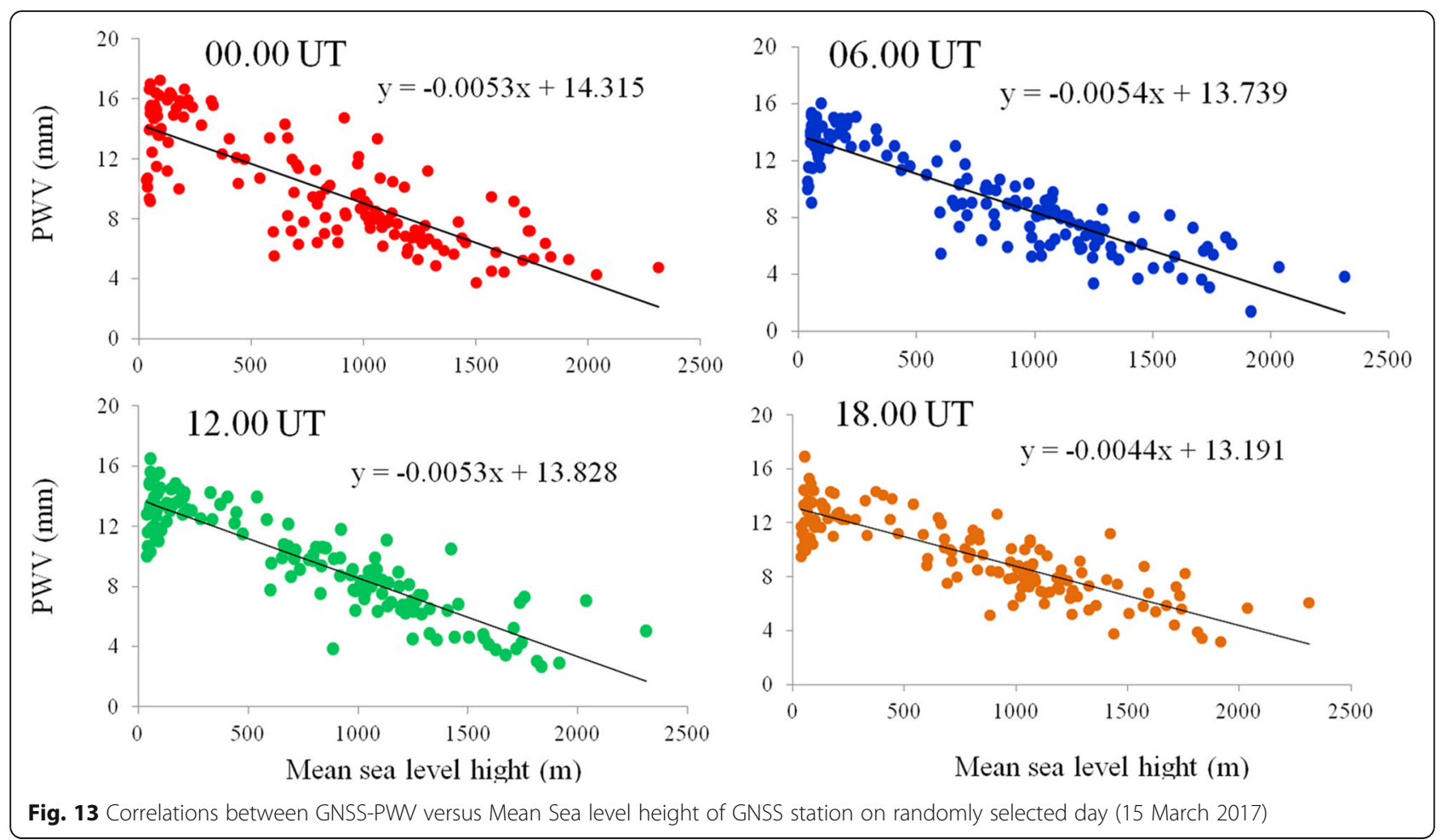

stations in Turkey. The PWV time series and the best fit line of six hourly data (00:00 UT, 06:00 UT, 12:00 UT and 18:00 UT) of the day on 15th of March 2017 has been shown in Fig. 13. It can be seen from the figure that the trend of PWV variation decreases with increasing altitude. This indicates that the PWV variation is large at lower altitude compared to higher altitude. These characteristics of PWV variation reflect the total variations of surface atmospheric pressure, atmospheric vertical motions, temperature and relative humidity etc. (Jin et al. 2007).

\section{PWV variability with rainfall}

The rainfall in the region is cumulative effect of high PWV and atmospheric parameters such as temperature, relative humidity wind, etc. while the PWV derived by GNSS point gives the total integrated water vapor (IWV) over the GNSS antenna. Recently, the correlation among PWV, rainfall and atmospheric temperature in the Turkish region was studied by Ansari et al. (2016). They tried to fit the relation of PWV, rainfall and temperature with the first-degree polynomial and found that the average correlation between modeled and observed GNSS-PWV from 2014 to 2015 varies from 67. $10 \%$ to $88.60 \%$ which represent a high correlation. We used $3 \mathrm{~A} 12$ version 7 rainfall data available in $0.5^{\circ} \times 0.5^{\circ}$ grid to investigate the variation of rainfall pattern in the Turkish region in relation to PWV (https://disc.gsfc.nasa. gov/services/opendap/TRMM/trmm.html). The data is calculated with vertical hydrometeor profiles as well as available mean surface rainfall. The rainfall data is available from December 1997 to March 2015 with the global area $40^{\circ} \mathrm{S}-40^{\circ} \mathrm{N}$ and $180^{\circ} \mathrm{W}-180^{\circ} \mathrm{E}$. Hence we choose the stations of Turkey which are following these boundary conditions. We studied the PWV variation with rainfall at selected four stations namely ANMU from south Turkey, CESM from western Turkey, GEME from central Turkey and SURF from southeast Turkey in the year 2009, 2011 and 2014. The average PWV values (in mm) from GNSS, ARMA and ERA-Interim and corresponding rainfall (in $\mathrm{cm}$ ) during the selected years are shown in Fig. 14. These results give the first look at the variation of rainfall and PWV for the sites. It can be seen that for GEME in the year of 2009 the PWV value coincides with the recorded high intensity of rainfall while the peak of the rainfall intensity is different in the year of 2011 and 2014. There is numerous research articles have been published that support the increase in PWV before rainfall but in some of the cases the PWV values reached maximum without rainfall (Priego et al., 2016). The maximum monthly rainfall usually follows the maximum PWV content, but the correlation between rainfall pattern and PWV is individual. The exact relationship is not fully understood yet; it depends upon the altitude and local or orographic features. The ANMU and CESM sites coincide with the peak rainfall intensity in starting month (January-April) of the year 2009 but other months have different pattern. The Fig. 14 clearly indicates that the rainfall pattern usually does not 


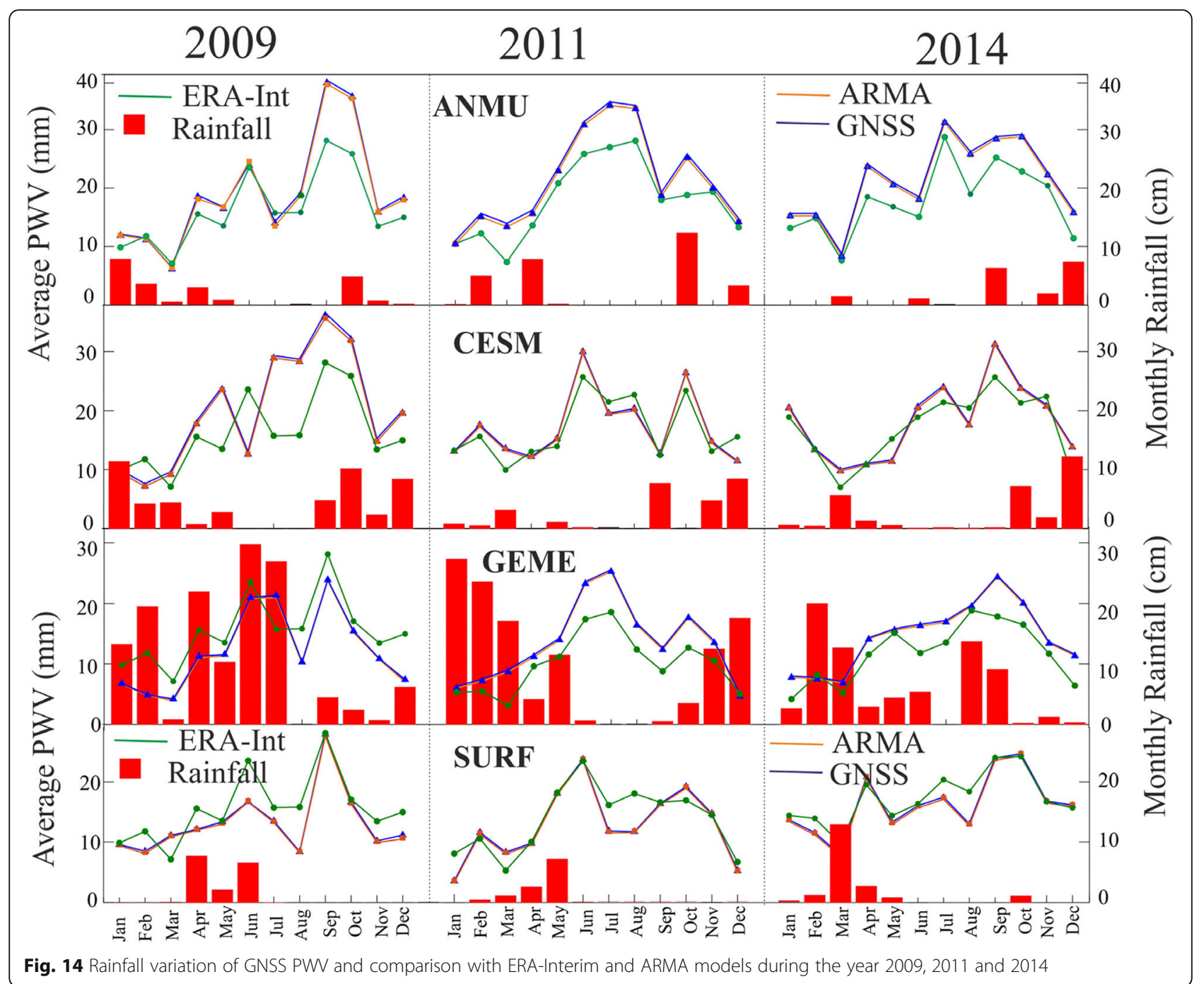

follow the PWV time series. Basically the maximum value of PWV along with pressure and relative humidity are associated with rainfall occurrences. The vertical atmospheric instability also works as precursor of heavy rainfall (Suseno et al. 2013). The conclusion is that including PWV other parameters like humidity, atmospheric instability should be considered together for the prediction of rainfall.

The GNSS derived PWV values during rainfall have been compared with the standard ARMA and ERAInterim models in the study to examine trustworthiness of the models over the lower middle latitude Turkish region. The differential calculation between the estimated values indicates the error in the model predictions. We analyzed the suitability of these model predictions covered by TPGN network and at adjacent locations using these techniques. The obtained results from Table 2 indicate the minimum and maximum relative error by ARMA and ERA-Interim models. The observed minimum relative errors by ARMA and ERAInterim models are $0.14 \%$ and $7.31 \%$ respectively while the maximum relative errors by ARMA and ERAInterim models are $0.24 \%$ and $15.28 \%$ respectively. These outcomes show the high-potential of stochastic component in regional PWV prediction on the TPGN regional network compared to ERA-Interim model in the terms of performance and accuracy. The GNSSPWV with ARMA-PWV model has perfect agreement but ERA-Interim has fluctuation with GNSS PWV. In conclusion, we can say that the ERA-Interim model require numerous computational points in the correction stage. These are the limitations of ERA-Interim model in PWV interpolations. Basically, the region of Turkey is a transition zone between low and middle latitudes, but still the estimation are less reliable. This proposes that, the lower and middle latitude region of Turkey needs further refinements with more regional data. The TPGN data can be incorporated in the ERA- 
Table 2 Relative and absolute errors of selected stations for the rainfall time variation of PWV

\begin{tabular}{|c|c|c|c|c|}
\hline Station Name & $\begin{array}{l}\text { Relative error } \\
\text { (Obs-ARMA) } \\
(\%)\end{array}$ & $\begin{array}{l}\text { Relative error } \\
\text { (Obs-ERA) } \\
(\%)\end{array}$ & $\begin{array}{l}\text { Absolute error } \\
\text { (Obs-ARMA) } \\
\text { (TECU) }\end{array}$ & $\begin{array}{l}\text { Absolute Erro } \\
\text { (Obs-ERA) } \\
\text { (TECU) }\end{array}$ \\
\hline ANMU & 0.14 & 15.28 & 0.029 & 3.124 \\
\hline CESM & 0.21 & 9.64 & 0.039 & 1.778 \\
\hline GEME & 0.14 & 7.31 & 0.019 & 0.980 \\
\hline SURF & 0.24 & 9.92 & 0.034 & 1.4010 \\
\hline
\end{tabular}

Interim experimental database for better reliability. We anticipate the dense TPGN data may complement towards further improvement in the global models above the territory. We tried to study the PWV variability with ARMA model techniques realizing discrepancies of the existing standard models over the region. The results from this study will help to improve the model estimations over Turkish as well as analogous lower mid-latitude regions.

\section{Summary}

We studied the tropospheric PWV variations at the lower middle latitude IGS and permanent GNSS stations across the Turkish region. The diurnal, seasonal, annual and spatial variations of the PWV have been investigated using GNSS derived PWV. The GNSS PWV observations and its comparison with predicted PWV from the ARMA and ERA-Interim models during the year 2009 to 2017 have been explained in detail. The key summary from the analysis are appended as follows;

i. The results illustrate that the diurnal cycle of PWV is maximum at the station located in Black sea region. The region has an oceanic climate with high and evenly distributed rainfall over the year. It has lower PWV value at night time which increases during the day because of the fast cooling of the landmass causes the breeze regime at night and in reverse blowing from land to sea during the day. The GNSS station located in Southeastern Anatolia Region showed the lowest PWV value. This region belongs to entirely the continental area and has a semi-arid continental climate. The station has lower value after 16.00 UT till midnight. The cooling of weather at this time is the reason of the PWV decrement by condensation. The diurnal variation of PWV cycle varies from time to time and season to season. The comparison graphs of the seasonal diurnal cycles show that the PWV cycle is clearly stronger in summer than the other seasons. The differences between PWV effects are lowest in winter, while in summer it has larger divergences.
The variation of PWV cycle in winter is quite similar at all places in spite of their geographical locations, but in summer, the strong local effects causes the diurnal cycle quite different among the stations. It is because the dispersions increase in spring time, and even more in autumn time. However, at some locations autumn and spring show transitional form between summer and winter at the Black sea region coast while the others are similar to the winter cycle.

ii. The seasonal PWV pattern over all stations depicts maximum in June solstice and September equinox and the minimum in December solstice and March equinox. The maximum average value reaches around $30 \mathrm{~mm}$ whereas the minimum average value is around $6 \mathrm{~mm}$. The values derived from ERAInterim model depict bias deviations in comparison to ARMA model at all sites. The percentage deviation of ARMA model is low. It means that our modeling using the local data is perfect than the ERA-Interim global model. The ERA-Interim model is generally underestimating the observed GNSS-PWV all the time for the BING, ZONG and IZMI stations while ANTE station shows overestimating characteristics. The percentage deviation of ERA Interim derived PWV is compared to ARMA model over the Turkish region; it indicates the necessity of further improvements in the ERA-Interim models. The RMSE is determined between GNSS PWV vs ERA-Interim PWV and GNSS PWV vs ARMA PWV values. The ERA-Interim model shows $\sim 4 \mathrm{~mm}$ RMSE over all station except $\sim 11 \mathrm{~mm}$ over ZONG located in Black sea region. However, ERA-Interim has less RMSE magnitudes $(\sim 2 \mathrm{~mm})$ at ANTE than others. This could be due to the less disturbed GNSS observed data at ANTE. The station is located in Southeastern Anatolia Region which is entirely in the vicinity of continental landmass receiving a semi-arid continental climate.

iii. The PWV annual variation shows that the range of PWV in Turkey is between 0 to $45 \mathrm{~mm}$. The PWV values at stations located closer to the coastal part of Turkey, for example, KIRL, BOYT, and ANTL 
show larger variation because the warm air holds more moisture and cold air is drier in these regions. The variation and magnitude of PWV are typically less at BOGZ, OZAL and SIVE. This is because these sites are situated in the continental inland which have generally less PWV annual variation than the coastal sites.

iv. The yearly relative deviations of PWV for each site are evaluated with the PWV obtained from the ERA-Interim and ARMA models which indicates the lower and upper quartiles per year monthly value during the period of 2009 to 2017. The outcomes of relative tropospheric PWV by the ARMA model is more precise than the ERA-Interim model. The relative deviations of ERA-Interim predicted PWV values follow the actual observations of GNSS-PWV over the Turkish region but they differ minutely in the magnitude. The PWV changeability lies in the range of -0.5 to 1.5 for the selected sites and the variation between negative-positive changeability is around two.

v. The highest grand-mean of PWV $(\sim 22 \mathrm{~mm})$ is registered in 2010 at ANTL while BOYT has maximum value $(\sim 21 \mathrm{~mm})$ in 2015 . The lower grand-mean of PWV $(\sim 11 \mathrm{~mm})$ is seen in 2011 and 2015 at OZAL stations. The grand-mean of PWV during 2009 is higher by $22 \mathrm{~mm}$ at ANTL. The values are lowered by $11 \mathrm{~mm}$ in 2011 and by $6 \mathrm{~mm}$ in 2017 at OZAL. The values of the annual grand-mean of PWV and corresponding values of ERA-Interim and ARMA models reproduce the delay in GNSS signal due to water vapor in Turkey. That perfect odd-even structures of grand-mean occur during the selected period, the values are decreasing in odd years (e.g. 2009, 2011, 2013, 2015 and 2017) and increasing in even years (e.g. 2010, 2013, 2014 and 2016) over the lower middle latitude Turkish region. The GNSS-PWV values of the annual grand-mean PWV intensity and corresponding values from ERA-Interim and ARMA models reproduce the water vapor as well as delay in GNSS signal over middle latitude Turkish region. The highest grand-mean variation of PWV intensity is noticed over the KIRL station in 2010, followed by ANTL in 2009 and 2015. Generally the measured grand-mean intensity variations of PWV values are in ascending phase in 2010, 2012, 2014 and 2015 months while in descending phase during 2013 and 2016. These outcomes show the annual anomaly, which is due to the change in composition of atmospheric constituents.

vi. The northern boundary of the Turkey, western part of the Country and Northern Cyprus have higher amounts of PWV while the other part of country like Central, Eastern Turkey has the lower amounts of PWV. Most of the GNSS sites showing higher amount of PWV are located relatively close to the coast of Black sea region and close to the Marmara and Aegean region in western part of the country. The northern Cyprus GNSS sites are situated close to the Mediterranean Sea. These regions have humid subtropical climate or hybrid Mediterranean climate on the south Mediterranean Sea coast and the coast of Aegean Sea, a humid continental climate in the interior and an oceanic climate on the Black sea coast. Most parts of the Eastern Anatolia, Central Anatolia and the Southeastern Anatolia Regions have low precipitation. These regions have continental climate with cold-snowy winters and hot-dry summers. The weather remains cool in the highlands and warm in the lowlands.

vii. The PWV values are coinciding well with high intensity of rainfall for GEME site in the year of 2009 while the peak of the rainfall intensity is different in the year of 2011 and 2014. The ANMU and CESM sites coincide with the peak rainfall intensity in starting month (January-April) of the year 2009 but other months have different pattern. The results clearly indicate that the rainfall pattern usually does not follow the PWV time series. The conclusion is that apart from PWV other parameters like humidity, atmospheric instability should be considered together for the prediction of rainfall.

viii.The GNSS derived PWV values during rainfall have been compared with the standard ARMA and ERAInterim models to examine reliability of the models over the lower mid-latitude Turkish region. The observed minimum relative errors by ARMA and ERA-Interim models are $0.23 \%$ and $24.80 \%$ respectively while the maximum relative errors by ARMA and ERA-Interim models are $1.17 \%$ and 25.79\% respectively. The GNSS-PWV with ARMA PWV model has perfect agreement but ERA-Interim has fluctuation with GNSS PWV.

Presently, the investigation is carried out with nine years GNSS PWV data from IGS stations and Turkish Permanent GNSS Network. The TPGN is available in dense from which can supplement and complement the utilization of regional PWV and can help in performances of large scale model predictions over the Turkish territory. There are very few studies on PWV and performance of model prediction with different kinds of datasets over the region. Hence, we wish the outputs from the analysis will be beneficial for understanding of water vapor and delays in GNSS signal over the Turkish region. 


\section{Acknowledgements}

The authors acknowledge TUSAGA-Aktif (https://www.tkgm.gov.tr/tr/icerik/ tusaga-aktif-0) for providing the TPGN data. The IGS GNSS stations data has been downloaded from the Scripps Orbit and Permanent Array Center (SOPAC; http://www.sopac.ucsd.edu). The ERA-Interim data set is obtained from ECMWF archives (http://apps.ecmwfint/datasets/data/interim-full-daily/ levtype $=\mathrm{sfc} /$ ), and Rainfall data is downloaded from the NASA TRMM website (https://disc.gsfc.nasa.gov/services/opendap/TRMM/ trmm.html). The authors express appreciations to Robert W. King for obtaining the GAMIT software used in this study.

\section{Authors' contributions}

All authors have an active part in the manuscript and concur with the submission by the corresponding author. First author has written the manuscript and made all figures, the second author has given Turkish data played an important role in English grammar. Third and fourth authors checked all the scientific explanation and corrected the grammar as well. We hope you find our manuscript suitable for publication and look forward to hearing from you at the earliest convenience. All authors read and approved the final manuscript.

\section{Competing interests}

We have written manuscript on the basis of our interest. The authors declare that they have no competing interests.

\section{Author details}

'Department of Civil and Geomatics Engineering, Kathmandu University, Dhulikhel, Nepal. ${ }^{2}$ Department of Geomatics Engineering, Izmir Katip Celebi University, Izmir, Turkey. ${ }^{3}$ Department of ECE, Koneru Lakshmaiah Education Foundation, Vaddeswaram, Guntur, A.P, India. ${ }^{4}$ Department of Electronics and Communication Engineering, Dayananda Sagar University, Bangalore, India.

\section{Received: 18 December 2017 Accepted: 13 April 2018}

\section{Published online: 03 May 2018}

\section{References}

Alshawaf, F., Dick, G., Heise, S., Simeonov, T., Vey, S., Schmidt, T. and Wickert, J., 2016. Decadal variations in atmospheric water vapor time series estimated using ground-based GNSS, http://www.atmos-meas-tech-discuss.net/amt2016-151/amt-2016-151.pdf. Accessed 26 Apr 2017.

Ansari K, Althuwaynee OF, Corumluoglu O (2016) Monitoring and prediction of Precipitable water vapor using GPS data in Turkey. J Appl Geodesy 10(4): 233245. https://doi.org/10.1515/jag-2016-0037

Ansari K, Corumluoglu O, Verma P (2017a) The triangulated affine transformation parameters and barycentric coordinates of Turkish permanent GPS network. Surv Rev:1-4. https://doi.org/10.1080/00396265.2017.1297016

Ansari K, Corumluoglu O, Panda SK (2017b) Analysis of ionospheric TEC from GNSS observables over the Turkish region and predictability of IRI and SPIM models. Astrophys Space Sci 332:65. https://doi.org/10.1007/s10509-017-3043-x

Ansari K, Panda SK, Althuwaynee OF, Corumluoglu O (2017c) lonospheric TEC from the Turkish permanent GNSS network (TPGN) and comparison with ARMA and IRI models. Astrophys Space Scie. https://doi.org/10.1007/s10509-017-3159-z

Ansari K, Panda SK, Corumluoglu O (2018) Mathematical modelling of ionospheric TEC from Turkish permanent GNSS network (TPGN) observables during 2009-2017 and predictability of NeQuick and kriging models. Astrophys Space Sci. https://doi.org/10.1007/s10509-018-3261-x

Bevis M, Businger S, Herring TA, Rocken C, Anthes RA, Ware RH (1992) GPS meteorology: remote sensing of atmospheric water vapor using the global positioning system. J of Geophys Res Atmos 97(D14):15787-15801. https://doi.org/10.1029/92jd01517

Bianchi CE, Mendoza LPO, Fernandez LI, Moitano JF (2016) Multiyear GNSS monitoring of atmospheric IWV over central and South America for climate studies. Ann Geo 34(7):623-639. https://doi.org/10.5194/angeo-34623-2016

Birkenheuer D, Gutman S (2005) A comparison of GOES moisture-derived product and GPS-IPW data during IHOP-2002. J Atmos Ocean Technol 22(11): 1838-1845. https://doi.org/10.1175/JTECH1814.1

Bock O, Keil C, Richard E, Flamant C, Bouin M-N (2005) Validation of Precipitable water from ECMWF model analyses with GPS and radiosonde data during the MAP SOP. Q J R Meteorol Soc 131(612):3013-3036. https://doi.org/10. 1256/qj.05.27
Boehm J, Kouba J, Schuh H (2009) Forecast Vienna mapping functions 1 for realtime analysis of space geodetic observations. J Geod 83(5):397-401. https://doi.org/10.1007/s00190-008-0216-y

Boehm J, Werl B, Schuh H (2006) Troposphere mapping functions for GPS and very long baseline interferometry from European Centre for Medium-Range Weather Forecasts Operational Analysis Data. J Geophys Res 111(B2):B02406. https://doi.org/10.1029/2005JB003629

Brenot H, Ducrocq V, Walpersdorf A, Champollion C, Caumont O (2006) GPS zenith delay sensitivity evaluated from high-resolution numerical weather prediction simulations of the 8-9 September 2002 flash flood over southeastern France. J Geophys Res Atmos 111(D15). https://doi.org/10.1029/ 2004jd005726

Campmany E, Bech J, Rodríguez-Marcos J, Sola Y, Lorente J (2010) A comparison of total precipitable water measurements from radiosonde and sunphotometers. Atmos Res 97(3):385-392. https://doi.org/10.1016/j.atmosres. 2010.04.016

Choy S, Wang CS, Yeh TK, Dawson J, Jia M, Kuleshov Y (2015) Precipitable water vapor estimates in the Australian region from ground-based GPS observations. Adv Meteorol. https://doi.org/10.1155/2015/956481

Dai A, Wang J, Ware RH, Van Hove T (2002) Diurnal variation in water vapor over North America and its implications for sampling errors in radiosonde humidity. J Geophys Res 107:4090. https://doi.org/10.1029/ 2001jd000642

Davis JL, Herring TA, Shapiro II, Rogers AEE, Elgered G (1985) Geodesy by radio interferometry: effects of atmospheric modeling errors on estimates of baseline length. Radio Sci 20(6):1593-1607. https://doi.org/10.1029/ RS020i006p01593

Elgered G, Davis JL, Herring TA, Shapiro II (1991) Geodesy by Radio Interferometry: Water Vapor Radiometry for Estimation of the Wet Delay. Journal of Geophysical Research 96(B4):6541. https://doi.org/10.1029/90JB00834.

Emardson TR, Elgered G, Johansson JM (1998) Three months of continuous monitoring of atmospheric water vapor with a network of global positioning system receivers. J Geophys Res 103(D2):1807. https://doi.org/10.1029/ 97JD03015

Fantini A, Raffaele F, Torma C, Bacer S, Coppola E, Giorgi F, Ahrens B, Dubois C, Sanchez E, Verdecchia M (2016) Assessment of multiple daily precipitation statistics in ERA-interim driven med-CORDEX and EURO-CORDEX experiments against high resolution observations. Clim Dyn:1-24. https://doi. org/10.1007/s00382-016-3453-4

Guerova G, Brockmann E, Schubiger F, Morland J, Mätzler C (2005) An integrated assessment of measured and modeled integrated water vapor in Switzerland for the period 2001-03. J Appl Meteorol 44(7):1033-1044. https://doi.org/10. 1175/JAM2255.1

Hadas T, Kaplon J, Bosy J, Sierny J, Wilgan K (2013) Near-real-time regional troposphere models for the GNSS precise point positioning technique. Measurement Science and Technology 24(5), p. 055003. http://iopscience.iop. org/article/10.1088/0957-0233/24/5/055003/meta.

Hadas T, Teferle FN, Kazmierski K, Hordyniec P, Bosy J (2016) Optimum stochastic modeling for GNSS tropospheric delay estimation in real-time. GPS Solutions: 1-13. https://doi.org/10.1007/s10291-016-0595-0

Hernandez-Pajares M, Juan JM, Sanz J, Colombo OL, van der Marel H (2001) A new strategy for real-time integrated water vapor determination in WADGPS networks. Geophys Res Lett 28(17):3267-3270. https://agupubs.onlinelibrary. wiley.com/doi/full/10.1029/2001GL012930

Herring TA, King RW, McClusky SC (2010) Introduction to Gamit/Globk. Massachusetts Institute of Technology, Cambridge http://chandler.mit.edu/ simon/gtgk/Intro_GG_10.3.pdf. Accessed 11 June 2017

Hopfield, H. S., 1972. Tropospheric range error parameters: further studies. https://ntrs.nasa.gov/archive/nasa/casi.ntrs.nasa.gov/19720020683.pdf. Accessed 04 June 2017

Jin S, Luo OF, Cho J (2009) Systematic errors between VLBI and GPS precipitable water vapor estimations from 5-year co-located measurements. J Atmos Sol Terr Phys 71(2):264-272. https://doi.org/10. 1016/j.jastp.2008.11.018

Jin SG, Park J, Cho J, Park P (2007) Seasonal variability of GPS-derived zenith tropospheric delay (1994-2006) and climate implications. J Geophys Res 112: D09110. https://doi.org/10.1029/2006jd007772

Li X, Dick G, Lu C, Ge M, Nilsson T, Ning T, Wickert J, Schuh H (2015) Multi-GNSS meteorology: real-time retrieving of atmospheric water vapor from BeiDou, Galileo, GLONASS, and GPS observations. IEEE Trans Geosci Remote Sens. https://doi.org/10.1109/TGRS.2015.2438395 
Liu Z, Chen B, Chan ST, Cao Y, Gao Y, Zhang K, Nichol J (2015) Analysis and modelling of water vapour and temperature changes in Hong Kong using a 40-year radiosonde record: 1973-2012. Int J Climatol 35(3):462-474. https:// doi.org/10.1002/joc.4001

Madonna E, Wernli H, Joos H, Martius O (2014) Warm conveyor belts in the ERA-interim dataset (1979-2010). Part I: climatology and potential vorticity evolution. J Clim 27(1):3-26. https://doi.org/10.1175/JCLI-D-1200720.1

Maghrabi AH, Al Dajani HM (2014) Time distribution of the precipitable water vapor in Central Saudi Arabia and its relationship to solar activity. Adv Space Res 53(8):1169-1179. https://doi.org/10.1016/j.asr.2014.02.006

Morland J, Collaud Coen M, Hocke K, Jeannet P, Mätzler C (2009) Tropospheric water vapour above Switzerland over the last 12 years. Atmos Chem Phys 9(16):5975-5988. http://www.atmos-chem-phys.net/9/5975/2009/

Nau, R., 2014. Notes on nonseasonal ARIMA models, Fuqua School of Business, Duke University, https://people.duke.edu/ rnau/forecasting.htm. Accessed 3 June 2017

Niell AE (1996) Global mapping functions for the atmosphere delay at radio wavelengths. J Geophys Res Solid Earth 101(B2):3227-3246. https://doi.org/ 10.1029/95jb03048

Nilsson T, Elgered G (2008) Long-Term Trends in the Atmospheric Water Vapor Content Estimated from Ground-Based GPS Data. Journal of Geophysical Research 113(D19):D19101. https://doi.org/10.1029/2008JD010110.

Ning T, Elgered G, Willén U, Johansson JM (2013) Evaluation of the atmospheric water vapor content in a regional climate model using ground-based GPS measurements. J Geophys Res Atmos 118(2):329-339. https://doi.org/10. 1029/2012JD018053

Ortiz de Galisteo JP, Cachorro V, Toledano C, Torres B, Laulainen N, Bennouna Y, de Frutos A (2011) Diurnal cycle of precipitable water vapor over Spain. Q J Roy Meteor Soc 137(657):948-958. https://doi.org/10.1002/qj.811

Panda SK, Gedam SS (2016) Evaluation of GPS standard point positioning with various ionospheric error mitigation techniques. J Appl Geodesy 10(4):211-221. https://doi.org/10.1515/jag-2016-0019

Peixoto JP, Salstein DA, Rosen RD (1981) Intra-annual variation in large-scale moisture fields. J Geophys Res Oceans 86(C2):1255-1264. https://doi.org/10. 1029/jc086ic02p01255

Priego E, Seco A, Jones J, Porres MJ (2016) Heavy rain analysis based on GNSS water vapour content in the Spanish Mediterranean area. Meteorol Appl 23(4):640-649. https://doi.org/10.1002/met.1586

Rocken C, Hove TV, Johnson J, Solheim F, Ware R, Bevis M, Chiswell S, Businger S (1995) GPS/STORM — GPS sensing of atmospheric water vapor for meteorology. J Atmos Ocean Technol 12(3):468-478. https://doi.org/10.1175/ 15200426(1995)012<0468:GSOAW> 2.0.CO;2

Rohm W, Yang Y, Biadeglgne B, Zhang K, Le Marshall J (2014) Ground-based GNSS ZTD/IWV estimation system for numerical weather prediction in challenging weather conditions. Atmos Res 138:414-426. https://doi.org/10. 1016/j.atmosres.2013.11.026

Saastamoinen J (1972) Contributions to the theory of atmospheric refraction. Bull Géod 105(1):279-298. https://doi.org/10.1007/bf02521844

Schmid R, Rothacher M, Thaller D, Steigenberger P (2005) Absolute phase center corrections of satellite and receiver antennas: impact on global GPS solutions and estimation of azimuthal phase center variations of the satellite antenna. GPS Solutions 9(4):283-293. https://doi.org/10.1007/ s10291-005-0134-X

Suseno Y, Prabowo D, Yamada TJ (2013) The role of GPS Precipitable water vapor and atmosphere stability index in the statistically based rainfall estimation using MTSAT data. J Hydrometeorol 14(6):1922-1932. https://doi.org/10.1175/JHM-D-12-0128.1

Thayer GD (1974) An improved equation for the radio refractive index of air. Radio Sci 9(10):803-807. http://ieeexplore.ieee.org/abstract/document/7773689/

Vedel H, Mogensen K, Huang XY (2001) Calculation of zenith delays from meteorological data comparison of NWP model, radiosonde and GPS delays. Phys Chem Earth 26:497-502. https://doi.org/10.1016/S14641895(01)00091-6

Wang H, Wei M, Li G, Zhou S, Zeng Q (2013) Analysis of precipitable water vapor from GPS measurements in Chengdu region: distribution and evolution characteristics in autumn. Adv Space Res 52(4):656-667. https://doi.org/10. 1016/j.asr.2013.04.005

Wang J, Zhang L, Dai A (2005) Global estimates of water-vapor-weighted mean temperature of the atmosphere for GPS applications. J Geophys Res 110(D21):1-17. https://doi.org/10.1029/2005JD006215
Yeh TK, Hong JS, Wang CS, Chen CH, Chen KH, Fong CT (2016) Determining the precipitable water vapor with ground-based GPS and comparing its yearly variation to rainfall over Taiwan. Adv Space Res 57(12):2496-2507. https://doi. org/10.1016/j.asr.2016.04.002

Zhang H, Yuan Y, Li W, Ou J, Li Y, Zhang B (2017) GPS PPP-derived precipitable water vapor retrieval based on tm/Ps from multiple sources of meteorological data sets in China. J Geophys Res Atmos 122(8):4165-4183. https://doi.org/10.1002/2016JD026000

\section{Submit your manuscript to a SpringerOpen ${ }^{\circ}$ journal and benefit from:}

- Convenient online submission

- Rigorous peer review

- Open access: articles freely available online

- High visibility within the field

- Retaining the copyright to your article

Submit your next manuscript at springeropen.com 